\title{
Posttransplantation cyclophosphamide prevents graft-versus-host disease by inducing alloreactive T cell dysfunction and suppression
}

\author{
Lucas P. Wachsmuth, ${ }^{1}$ Michael T. Patterson, ${ }^{1}$ Michael A. Eckhaus, ${ }^{2}$ David J. Venzon, ${ }^{3}$ Ronald E. Gress, ${ }^{1}$ and Christopher G. Kanakry ${ }^{1}$
}

${ }^{1}$ Experimental Transplantation and Immunology Branch, Center for Cancer Research, National Cancer Institute (NCI), ${ }^{2}$ Division of Veterinary Resources, Office of Research Services, ${ }^{3}$ Biostatistics and Data Management Section, Office of the Clinical Director, Center for Cancer Research, NCI, NIH, Bethesda, Maryland, USA.

\begin{abstract}
Posttransplantation cyclophosphamide (PTCy) recently has had a marked impact on human allogeneic hematopoietic cell transplantation (HCT). Yet our understanding of how PTCy prevents graft-versus-host disease (GVHD) largely has been extrapolated from MHC-matched murine skin-allografting models that were highly contextual in their efficacy. Herein, we developed a T cell-replete, MHC-haploidentical, murine HCT model (B6C3F1 $\rightarrow$ B6D2F1) to test the putative underlying mechanisms: alloreactive T cell elimination, alloreactive $\mathrm{T}$ cell intrathymic clonal deletion, and suppressor $\mathrm{T}$ cell induction. In this model and as confirmed in four others, PTCy did not eliminate alloreactive T cells identified using either specific V $\beta s$ or the $2 \mathrm{C}$ or $4 \mathrm{C}$ T cell receptors. Furthermore, the thymus was not necessary for PTCy's efficacy. Rather, PTCy induced alloreactive T cell functional impairment, which was supported by highly active suppressive mechanisms established within one day after PTCy that were sufficient to prevent new donor T cells from causing GVHD. These suppressive mechanisms included the rapid, preferential recovery of $\mathrm{CD} 4^{+} \mathrm{CD} 25^{+} \mathrm{Foxp}^{+}$regulatory $\mathrm{T}$ cells, including those that were alloantigen specific, which served an increasingly critical function over time. Our results prompt a paradigm shift in our mechanistic understanding of PTCy. These results have direct clinical implications for understanding tolerance induction and for rationally developing novel strategies to improve patient outcomes.
\end{abstract}

\section{Introduction}

Although potentially curative for many otherwise incurable hematologic malignancies, allogeneic hematopoietic cell transplantation (HCT) historically was inaccessible to many patients for lack of HLA-matched donors $(1,2)$. Nearly all patients have HLAhaploidentical donors, but early results of HLA-haploidentical HCT showed high mortality due to prohibitive rates of severe graft-versus-host disease (GVHD) $(2,3)$.

Novel clinical approaches, including posttransplantation cyclophosphamide (PTCy), now safely facilitate HLA-haploidentical HCT (2). It is standard for PTCy to be given at $50 \mathrm{mg} / \mathrm{kg} / \mathrm{d}$ on days +3 and +4 and to be used alone or in combination with other GVHD prophylactic agents depending on the characteristics, including donor type, of the HCT platform (2). Regardless of the platform, PTCy prevents both severe acute and chronic GVHD (2), minimizes the need for other immunosuppression $(4,5)$, and preserves infectious immunity $(2,6-9)$, ultimately resulting in low rates of nonrelapse mortality. Since malignancy recurrence rates appear similar to those with standard $\operatorname{HCT}(4,10)$, recent registry

\section{Related Commentary: p. 2189}

Authorship note: LPW and MTP contributed equally to this work. Conflict of interest: The authors have declared that no conflict of interest exists. Copyright: () 2019, American Society for Clinical Investigation. Submitted: August 16, 2018; Accepted: March 19, 2019; Published: May 6, 2019 Reference information: / Clin Invest. 2019;129(6):2357-2373. https://doi.org/10.1172/JCl124218. studies suggest that HLA-haploidentical HCT with PTCy results in similar survival, but lower chronic GVHD rates, compared with HLA-matched HCT using standard GVHD prophylaxis (11-13). Long-term outcomes are not yet known, but PTCy does not appear to be associated with increased rates of late toxicities, such as secondary malignancies (14). Furthermore, PTCy is relatively inexpensive and its administration requires little specialized expertise or infrastructure. Consequently, PTCy-based HLA-haploidentical HCT is rapidly increasing worldwide.

Yet limited mechanistic data in HCT models existed prior to PTCy's successful clinical translation (15). PTCy was most fully developed preclinically in MHC-matched murine skin-allografting models, where, combined with donor splenocyte infusion 2 to 3 days beforehand, PTCy effectively prevented rejection of subsequently placed skin allografts $(16,17)$. Exploiting strain-specific differential expression of certain $\mathrm{T}$ cell receptor (TCR) V $\beta s$ as markers of alloreactive cells (18), these studies found a marked decrease in alloreactive $\mathrm{CD}^{+}$, but not $\mathrm{CD} 8^{+}$, $\mathrm{T}$ cells in PTCy-treated mice $(19,20)$. Thus, PTCy was believed to work via selective alloreactive $\mathrm{T}$ cell elimination, thought to occur primarily through direct destruction of alloreactive T cells proliferating at the time of PTCy and secondarily via intrathymic clonal deletion of alloreactive $\mathrm{T}$ cell precursors (19-22). Suppressor T cells were shown to play an adjunct role in maintaining tolerance, although there was discrepancy regarding whether these were $\mathrm{CD}^{+}$or $\mathrm{CD}^{+}(20,23,24)$.

The relevance of these findings to HCT remains unclear. PTCy's effectiveness in skin-allografting models was highly contextual, requiring specific MHC-matching, type and dose of donor 
cells, PTCy dose, and recipient age (25-27). Indeed, PTCy failed to prevent rejection of MHC-mismatched skin allografts without multiple rounds of PTCy or combination with $\mathrm{T}$ cell-depleting antibodies $(16,28)$. These findings are at odds with the broad effectiveness of PTCy in human HCT across a wide range of recipient ages and donor graft types, cell doses, and HLA matching $(2,5,29)$.

Moreover, there is a fundamental disconnect between the mechanisms described in murine skin-allografting models and clinical observations in human HCT. Rates of grade II (clinically significant but not severe) acute GVHD after PTCy-based HCT are 30\%-80\% $(2,5,30-32)$, indicating that alloreactive $\mathrm{T}$ cell elimination is not achieved in these patients. Even so, only approximately $10 \%-20 \%$ of patients develop chronic GVHD $(2,5,30-32)$, indicating no ongoing clinical alloreactivity despite alloreactive $\mathrm{T}$ cell persistence. This disconnect led us to consider the mechanistic importance of $\mathrm{CD}^{+}$Tregs in PTCy-mediated GVHD prevention, revealing that Tregs were resistant to PTCy in HLA-mismatched mixed lymphocyte cultures (33), recovered rapidly after HCT in humans (33), and were necessary immediately after transplant for GVHD prevention by PTCy in xenogeneic (33) and MHC-matched (34) murine HCT models. Other groups have reported that PTCy preferentially targets $\mathrm{T}$ cells undergoing antigen-driven rather than lymphopenia-driven proliferation in MHC-matched murine HCT (35) and that T cells of a stem cell-memory phenotype dominate early immune reconstitution after HLA-haploidentical HCT $(36,37)$. Yet the accepted paradigm of how PTCy prevents GVHD in HCT is still largely extrapolated from the murine MHC-matched skin-allografting studies (38).

To better understand the biology of tolerance induction and specifically how PTCy prevents GVHD in order to rationally improve clinical outcomes, we developed an MHC-haploidentical HCT model that directly parallels human HLA-haploidentical HCT. We used this model to probe the central tenets of the existing paradigm (38), specifically testing the hypothesis that selective elimination of alloreactive $\mathrm{T}$ cells is a central and necessary mechanism of PTCy-mediated GVHD prevention after HCT.

\section{Results}

PTCy effectively controls GVHD in a T cell-replete, MHC-haploidentical HCT model (B6C3F1 $\rightarrow B 6 D 2 F 1)$. On day 0, B6D2F1 $\left(\mathrm{H} 2 \mathrm{k}^{\mathrm{d}+} \mathrm{H} 2 \mathrm{k}^{\mathrm{b}+}\right)$ recipient mice were lethally irradiated and transplanted with B6C3F1 (H2 $\left.\mathrm{k}^{\mathrm{k}+} \mathrm{H} 2 \mathrm{k}^{\mathrm{b}+}\right) \mathrm{T}$ cell-depleted (TCD) BM \pm splenocytes. As splenocytes contain T cells that mediate GVHD, splenocyte doses of $40 \times 10^{6}$ or more caused universally fatal GVHD, while lower doses resulted in fatal GVHD only in a subset of mice (Supplemental Figure 1; supplemental material available online with this article; https://doi.org/10.1172/JCI124218DS1). Consequently, a splenocyte dose of $40 \times 10^{6}$ cells was used. The median T cell $\left(\mathrm{CD}^{+}\right)$content of B6C3F1 splenocytes was $34.3 \%$ (IQR, 31.8\%-37.1\%), while the median T cell content of B6C3F1 BM was $1.65 \%$ (IQR 1.4\%-1.88\%) before TCD and $0.3 \%$ (IQR $0.2 \%-0.48 \%)$ after TCD. The levels of phenotypic $\mathrm{CD} 4^{+} \mathrm{CD} 25^{+}$ Foxp $3^{+}$Tregs and myeloid-derived suppressor cells in the spleens and BM of B6C3F1 mice are shown in Supplemental Figure 2.

PTCy was administered on days +3 and +4 to parallel clinical practice (2). PTCy doses between 10 and $50 \mathrm{mg} / \mathrm{kg} / \mathrm{d}$ effectively prevented fatal GVHD, with $25 \mathrm{mg} / \mathrm{kg} / \mathrm{d}$ being the optimal tested dose in this model (Figure $1 \mathrm{~A})$. Doses outside this range $(\leq 5$ or $\geq 100 \mathrm{mg} / \mathrm{kg} / \mathrm{d}$ ) proved ineffective in preventing mortality (Figure 1, A and B, and Supplemental Figure 3). Full donor T cell chimerism was observed by day +21 in mice treated with splenocytes with or without PTCy (Figure 1, C and D).

Histopathologic assessment (Supplemental Table 1) at days +7 and +21 showed that mice treated with $25 \mathrm{mg} / \mathrm{kg} / \mathrm{d}$ PTCy had minimal to mild GVHD, which was significantly less severe than that observed in mice treated with vehicle or with ineffectively low $(5 \mathrm{mg} / \mathrm{kg} / \mathrm{d})$ or high $(100 \mathrm{mg} / \mathrm{kg} / \mathrm{d})$ PTCy doses (Figure 1, $\mathrm{E}$ and F, and Supplemental Table 2). Mice treated with $25 \mathrm{mg} / \mathrm{kg}$ PTCy had a characteristic and reproducible loss in weight occurring between days +50 and +90 that was dramatic but transient for a given mouse (Figure 1A and Supplemental Figure 4) and was accompanied by worsening clinical scores during this period. Histopathologic assessment $(n=10)$ at day +50 showed focal proliferative and ulcerative intestinal lesions in half of the mice (Supplemental Figure 4), which may account for these clinical changes. Yet mice nearly always recovered, steadily gaining weight and normalizing their clinical scores after days +90-100. This phenomenon was not observed or was observed only to a limited extent in mice treated with TCD BM and PTCy without splenocytes (Supplemental Figure 5). Mice treated with $100 \mathrm{mg} / \mathrm{kg}$ PTCy had significantly worse GVHD histopathologically at day +21 compared with mice treated with $25 \mathrm{mg} / \mathrm{kg}$ PTCy (Figure 1F), but drug toxicity appeared to be a major contributing cause of late morbidity and mortality after the higher dose (Supplemental Figure 3). At day +200 , surviving mice treated with PTCy, regardless of dose, had no histopathologic evidence of cutaneous, hepatic, gastrointestinal, or pulmonary GVHD.

Optimally dosed PTCy does not induce pan-T cell depletion, and even high-dose PTCy leads to immune reconstitution markedly distinct from TCD HCT. Some have asserted that PTCy works via in vivo $\mathrm{T}$ cell depletion. Total numbers of $\mathrm{T}$ cells recovered from blood, peripheral lymph nodes, spleen, and liver at day +7 were lower in $25 \mathrm{mg} / \mathrm{kg}$ PTCy-treated mice than in vehicle-treated mice, but were in the same log range (Figure 2A). In fact, the numbers of $\mathrm{T}$ cells infiltrating the liver, a GVHD target organ, were higher in mice treated with allogeneic splenocytes and $25 \mathrm{mg} / \mathrm{kg}$ PTCy than in syngeneic controls. $100 \mathrm{mg} / \mathrm{kg}$ PTCy did result in broad reductions in $\mathrm{T}$ cell numbers at day +7 , but $\mathrm{T}$ cell numbers greatly rebounded by day +21 (Figure $2 \mathrm{~B}$ ). Furthermore, the composition of recovering leukocyte subsets in mice treated with $100 \mathrm{mg} / \mathrm{kg}$ PTCy remained markedly dissimilar from that in mice treated with TCD BM alone, but rather similar to that in mice treated with splenocytes and either vehicle or lower PTCy doses (Supplemental Figure 6). Thus, any T cell-depleting effect of the highest PTCy dose appears immunologically distinct from that with ex vivo TCD.

Optimally dosed PTCy significantly reduces $C D 4^{+}$but not $C D 8^{+}$ $T$ cell proliferation. PTCy is thought to preferentially kill proliferating $\mathrm{T}$ cells, contributing to its putative role in alloreactive $\mathrm{T}$ cell elimination (38). High proliferation $\left(\mathrm{Ki}-67^{+}\right)$rates were seen at day +7 in both $\mathrm{CD}^{+}$and $\mathrm{CD} 8^{+} \mathrm{T}$ cell subsets of vehicle-treated mice (Figure $2 \mathrm{C}$ ), consistent with high $\mathrm{T}$ cell proliferation $\left(\mathrm{Ki}-67^{+}\right)$rates observed early after transplant in humans treated with HLA-haploidentical HCT $(36,37)$. With increasing PTCy doses in our model, decreasing $\mathrm{CD}^{+}{ }^{+} \mathrm{T}$ cell proliferation was seen. However, 25 $\mathrm{mg} / \mathrm{kg}$ PTCy did not significantly reduce $\mathrm{CD} 8^{+} \mathrm{T}$ cell proliferation in nonblood tissue compartments; only with $100 \mathrm{mg} / \mathrm{kg}$ PTCy, a 


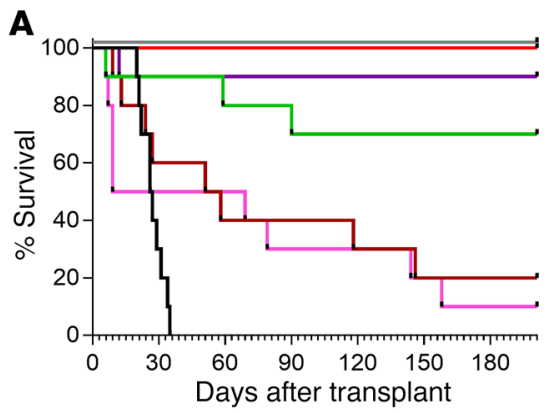

- TCD BM, vehicle

- TCD BM, splen, vehicle

- TCD BM, splen, PTCy $10 \mathrm{mg} / \mathrm{kg} \mathrm{d}+3,+4$

— TCD BM, splen, PTCy $25 \mathrm{mg} / \mathrm{kg} \mathrm{d}+3,+4$

- TCD BM, splen, PTCy $50 \mathrm{mg} / \mathrm{kg} \mathrm{d}+3,+4$

- TCD BM, splen, PTCy $100 \mathrm{mg} / \mathrm{kg} \mathrm{d}+3,+4$

— TCD BM, splen, PTCy $200 \mathrm{mg} / \mathrm{kg} \mathrm{d}+3$

B
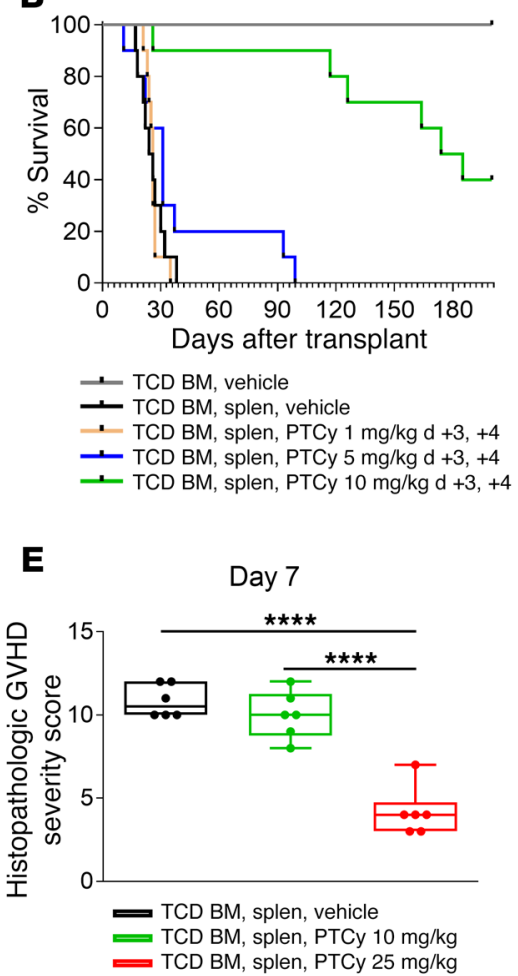
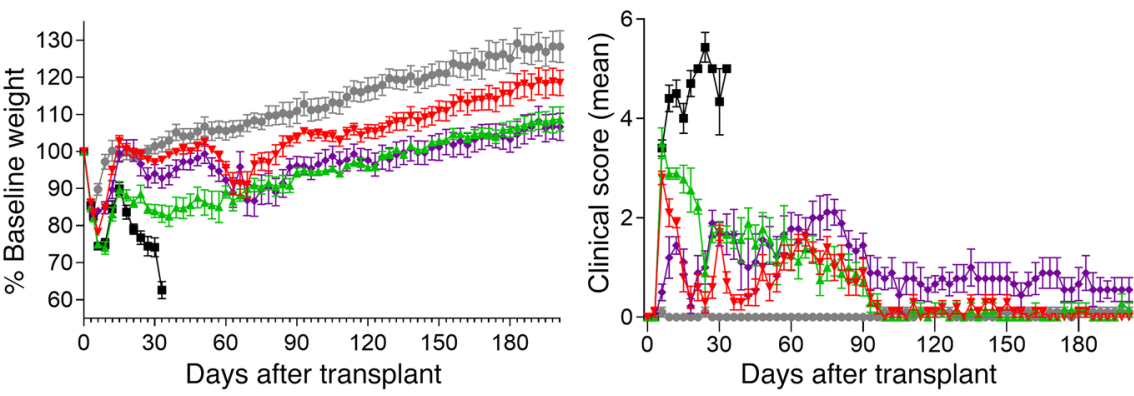

- -TCD BM, vehicle

- TCD BM, splen, vehicle

- TCD BM, splen, PTCy $10 \mathrm{mg} / \mathrm{kg} \mathrm{d} \mathrm{+3,} \mathrm{+4}$

- - TCD BM, splen, PTCy $25 \mathrm{mg} / \mathrm{kg} \mathrm{d}+3,+4$

$\longrightarrow$ TCD BM, splen, PTCy $50 \mathrm{mg} / \mathrm{kg} \mathrm{d}+3,+4$

C

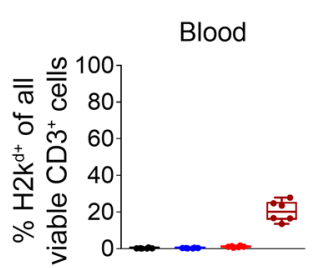

Day 7
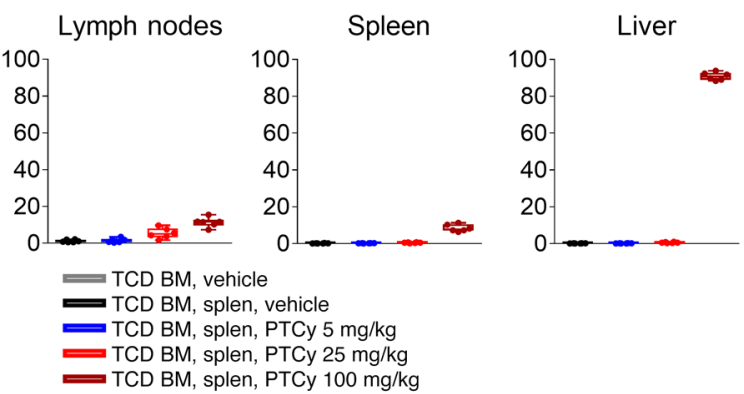

Day 21

Blood
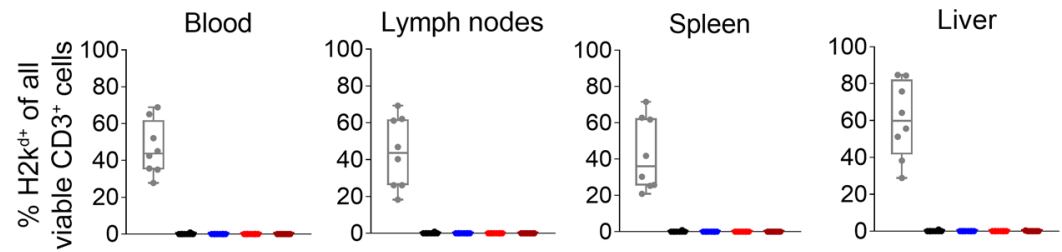

$\mathbf{F}$

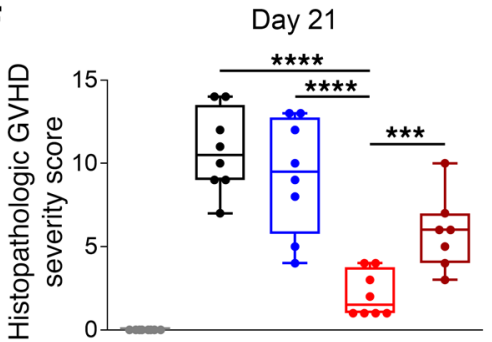

TCD BM, vehicle

TCD BM, splen, vehicle

TCD BM, splen, PTCy 5 mg/kg

TCD BM, splen, PTCy $25 \mathrm{mg} / \mathrm{kg}$

TCD BM, splen, PTCy $100 \mathrm{mg} / \mathrm{kg}$

Figure 1. In a T cell-replete, MHC-haploidentical, murine HCT model (B6C3F1 $\rightarrow$ B6D2F1), optimally dosed PTCy prevents severe GVHD. On day 0,10 - to 12-week-old recipient female B6D2F1 mice were irradiated (10.5 Gy) and transplanted with $10 \times 10^{6}$ TCD BM cells $\pm 40 \times 10^{6}$ splenocytes (splen) from 10- to 12-week-old female B6C3F1 donors. PBS vehicle or PTCy was administered on days +3 and +4 . (A) PTCy doses of 10-50 mg/kg/d prevented lethality and resulted in steadily increasing weights and normalization of clinical scores after days $+90-100$. (B) PTCy doses of 1 or 5 mg/ $\mathrm{kg} / \mathrm{d}$ were ineffective in preventing fatal GVHD. (C and $\mathbf{D})$ Mice receiving T cell-replete grafts with or without PTCy became full donor T cell chimeras by day (C) +7 to $(\mathbf{D})+21$. (E and F) Mice treated with the optimal dose of PTCy $(25 \mathrm{mg} / \mathrm{kg})$ in this model had only mild histopathologic evidence of GVHD at either day (E) +7 or $(\mathbf{F})+21$. Combined results from $(\mathbf{A}, \mathbf{B}, \mathbf{D}-\mathbf{F}) 2$ or $(\mathbf{C}) 3$ independent experiments are shown. $n=10 /$ group for $\mathbf{A}$ and $\mathbf{B} ; n=$ 6/group for $\mathbf{C}$ and $\mathbf{E}$; and $n=8 /$ group for $\mathbf{D}$ and $\mathbf{F}$ except for the $100 \mathrm{mg} / \mathrm{kg}$ PTCy groups in $\mathbf{D}(n=5)$ and $\mathbf{F}(n=7)$. ${ }^{* *} P \leq 0.001 ;{ }^{* * * *} P \leq 0.0001,1-$ way ANOVA followed by the Holm-Šidák post hoc test.

dose associated with worse GVHD in this model, was $\mathrm{CD}^{+} \mathrm{T}$ cell proliferation at day +7 largely halted.

PTCy does not eliminate alloreactive $T$ cells regardless of PTCy dose or HCT model. The central tenet of the existing paradigm is that PTCy primarily works by selectively eliminating alloreactive $\mathrm{T}$ cells (38). In our $\mathrm{B} 6 \mathrm{C} 3 \mathrm{~F} 1 \rightarrow \mathrm{B} 6 \mathrm{D} 2 \mathrm{~F} 1$ model, $\mathrm{V} \beta 6 \mathrm{TCR}^{+}$donor $\mathrm{T}$ cells are alloreactive, as they have specificity for the endogenous superantigen provirus MMTV7 incorporated into the B6D2F1 
A Day 7

B Day 21
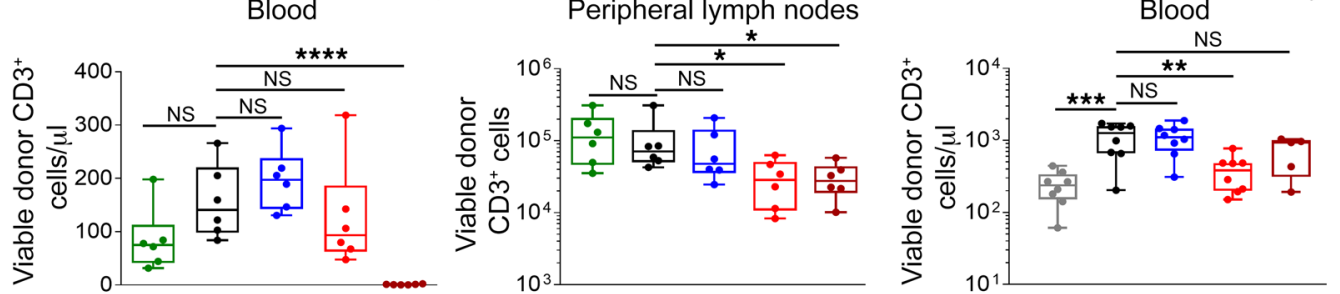

Peripheral lymph nodes
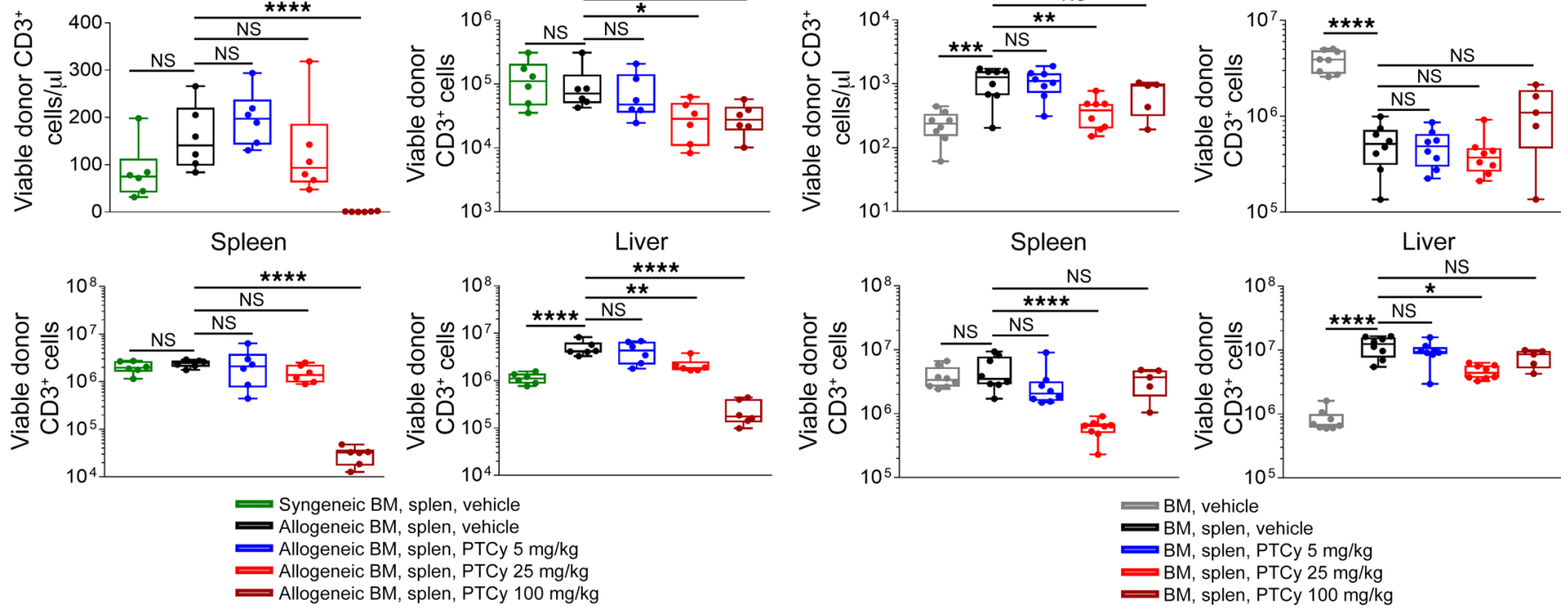

C

Day 7

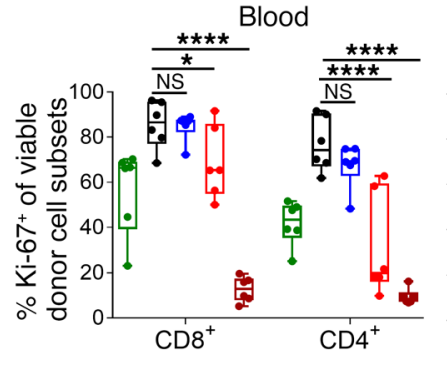

Peripheral lymph nodes

Spleen

Liver
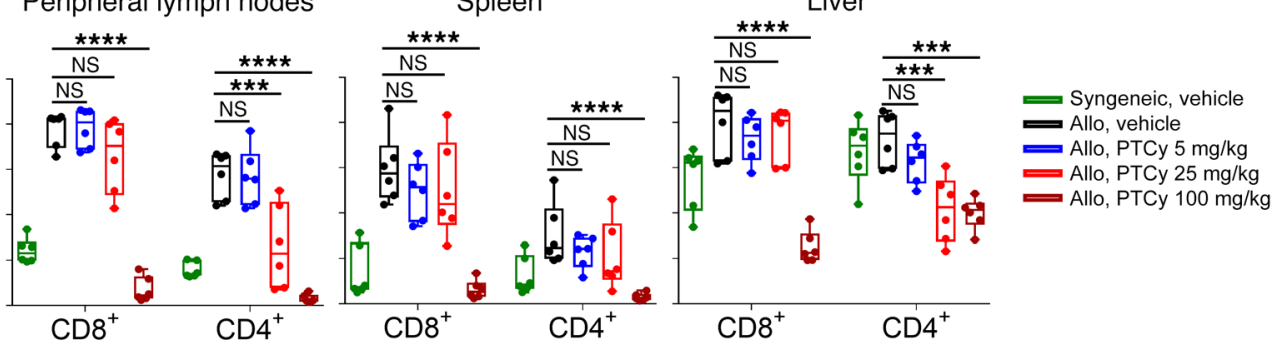

D
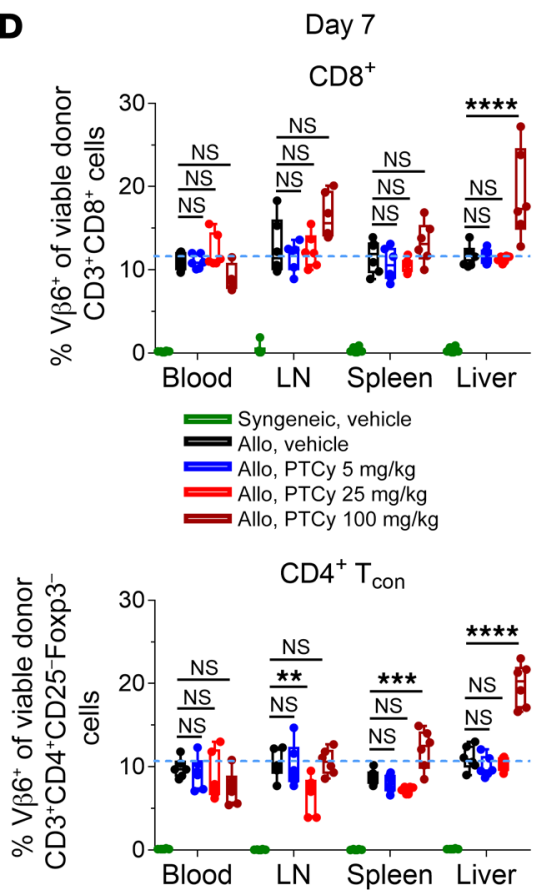

E

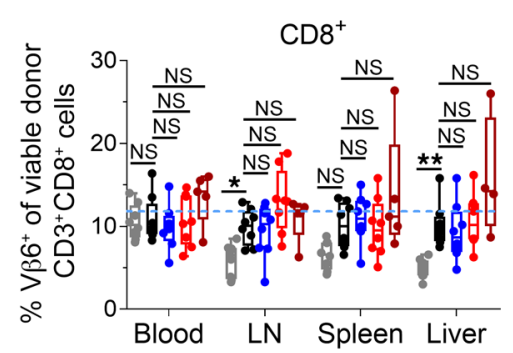

BM, vehicle

BM, splen, vehicle

BM, splen, PTCy $5 \mathrm{mg} / \mathrm{kg}$

BM, splen, PTCy $25 \mathrm{mg} / \mathrm{kg}$

BM, splen, PTCy $100 \mathrm{mg} / \mathrm{kg}$

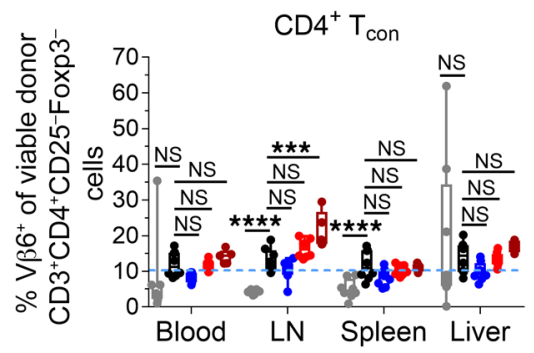

$\mathbf{F}$

Day 200

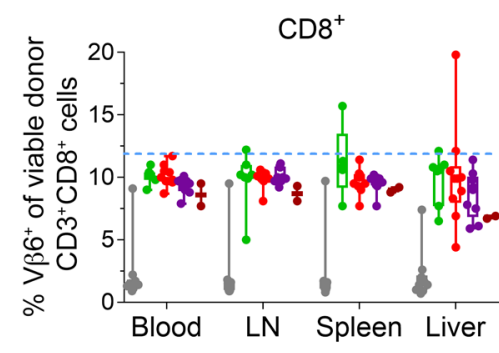

BM, splen, PTCy $10 \mathrm{mg} / \mathrm{kg}$ BM, splen, PTCy $25 \mathrm{mg} / \mathrm{kg}$ BM, splen, PTCy $50 \mathrm{mg} / \mathrm{kg}$ BM, splen, PTCy $100 \mathrm{mg} / \mathrm{kg}$

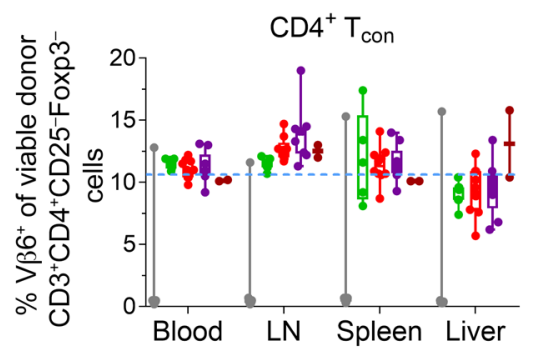


Figure 2. Optimally dosed PTCy neither induces pan-T cell depletion nor eliminates alloreactive $\mathrm{T}$ cells, but does reduce $\mathrm{CD4}^{+} \mathrm{T}$ cell proliferation. Mice were transplanted as in Figure 1 and assessed at day $+7,+21$, or +200 . All groups were allogeneic (Allo, B6C3F1 $\rightarrow$ B6D2F1) unless specifically labeled as syngeneic (B6D2F1 $\rightarrow$ B6D2F1). (A and B) T cell numbers in different tissue compartments at day $(\mathbf{A})+7$ or $(\mathbf{B})+21$. (C) High global T cell proliferation $\left(\mathrm{Ki}-67^{+}\right)$was observed at day +7 . CD4 ${ }^{+}$ $T$ cell proliferation was reduced with increasing doses of PTCy, while $\mathrm{CD}^{+} \mathrm{T}$ cells continued to proliferate robustly despite treatment with $25 \mathrm{mg} / \mathrm{kg}$ PTCy. Only after $100 \mathrm{mg} / \mathrm{kg}$ PTCy was CD8+ T cell proliferation significantly reduced. (D-F) Regardless of PTCy treatment or dose, alloreactive $\mathrm{V} \beta 6^{+} \mathrm{T}$ cells persisted at levels similar to those seen in donors (dotted blue line; median values from Supplemental Figure 7: $\mathrm{CD}^{+}, 11.9 \%$; CD4+CD25-Foxp3- conventional T cells [CD4+ ${ }^{+} \mathrm{T}_{\text {cons }}$ ], 10.5\%) and even exceeded donor levels in the spleen and liver at day +7 after $100 \mathrm{mg} / \mathrm{kg}$ PTCy. These effects contrast with those in mice treated with TCD BM without PTCy in which $\mathrm{V} \beta 6^{+} \mathrm{T}$ cells were deleted over time. Combined results from (A, C, D) 3 ( $n=6 /$ group) or (B, E) 2 ( $n=8 /$ group except $100 \mathrm{mg} / \mathrm{kg}$ PTCy $[n=5]$ ) independent experiments are shown. $\mathbf{F}$ shows data from all mice from Figure $1 \mathrm{~A}$ surviving to day +200 . ${ }^{*} P \leq 0.05 ;{ }^{* *} P \leq 0.01 ;{ }^{* *} P \leq 0.001 ;{ }^{* * *} P \leq 0.0001$, 1-way ANOVA followed by the Holm-Šidák post hoc test using the vehicle-treated splenocyte group as the control. LN, peripheral lymph nodes.

genome (18). We found that $\mathrm{V} \beta 6^{+} \mathrm{CD} 8^{+}$and $\mathrm{V} \beta 6^{+}$conventional $\mathrm{CD}^{+} \mathrm{CD} 25^{-}{ }^{-}$oxp $33^{-}$donor $\mathrm{T}$ cells were not eliminated at day +7 by PTCy (Figure 2D), but rather persisted at percentages similar to those seen in donors (Supplemental Figure 7). This persistence was seen regardless of PTCy dose; indeed, $\mathrm{V} \beta 6^{+}$percentages of $\mathrm{CD} 4^{+} \mathrm{T}$ cells actually were significantly increased in the spleen and liver of mice treated with $100 \mathrm{mg} / \mathrm{kg}$ PTCy (Figure 2D). The persistence of ${\mathrm{V} \beta 6^{+}}^{+} \mathrm{T}$ cells near or above percentages seen in donors continued at days +21 and +200 (Figure $2, \mathrm{E}$ and F).

Total numbers of $\mathrm{V} \beta 6^{+} \mathrm{CD} 4^{+} \mathrm{CD} 25^{-} \mathrm{Foxp}^{-}$, but not $\mathrm{V} \beta 6^{+} \mathrm{CD} 8^{+}$, $\mathrm{T}$ cells did significantly decline at day +7 after $25 \mathrm{mg} / \mathrm{kg} / \mathrm{d}$ PTCy on days +3 and +4 , but still remained within the same log range as that observed in vehicle-treated mice (Supplemental Figure 8, A and B). Expansion of $\mathrm{V} \beta 6^{+} \mathrm{CD} 4^{+} \mathrm{CD} 25^{-} \mathrm{Foxp}^{-}$and $\mathrm{V} \beta 6^{+} \mathrm{CD} 8^{+} \mathrm{T}$ cell numbers from day +7 to day +21 was constrained in mice treated with $25 \mathrm{mg} / \mathrm{kg}$ PTCy. In contrast, in mice treated with $100 \mathrm{mg} /$ kg PTCy, $\mathrm{V} \beta 6^{+} \mathrm{CD} 4^{+} \mathrm{CD} 25^{-}{ }^{-}{ }^{-}{ }^{-} 3^{-}$and $\mathrm{V} \beta 6^{+}{ }^{+} \mathrm{CD} 8^{+} \mathrm{T}$ cell numbers substantially rebounded by day +21 to levels found in vehicletreated mice (Supplemental Figure 8, C and D), potentially contributing to the worse GVHD observed histopathologically at that time point in mice treated with $100 \mathrm{mg} / \mathrm{kg}$ PTCy (Figure 1F).

Persistence of alloreactive $\mathrm{V} \beta 6^{+} \mathrm{T}$ cells after PTCy also was seen in other murine HCT models, including another MHC-haploidentical (B6 $\rightarrow$ B6D2F1; day +7$)$, an MHC-disparate $(\mathrm{C} 3 \mathrm{H} \rightarrow \mathrm{B} 6 \mathrm{D} 2 \mathrm{~F} 1$; days +6 and +200$)$, and an MHC-matched $(\mathrm{C} 3 \mathrm{H} \rightarrow \mathrm{AKR}$; day +7$)$ model (Supplemental Figure 9, Supplemental Figure 10, and Supplemental Figure 11). Furthermore, persistence of alloreactive $\mathrm{V} \beta 3$ and $\mathrm{V} \beta 5 \mathrm{TCR}^{+} \mathrm{T}$ cells after PTCy was observed at day +7 in a B6 $\rightarrow$ B6C3F1 MHC-haploidentical model (Supplemental Figure 12). In some models, the percentages of alloreactive T cells were reduced by PTCy compared with those in vehicle-treated mice, but this appeared related to curbing preferential expansion of alloreactive $\mathrm{T}$ cells, as the percentages remained near or frequently above donor percentages. Nevertheless, severe GVHD was abated by PTCy in these models (Figure
1A and Supplemental Figure 10) (15), demonstrating that selective alloreactive $\mathrm{T}$ cell elimination is not a necessary mechanism underlying PTCy-mediated GVHD prophylaxis.

Alloreactive $2 C T C R^{+} T$ cells persist and expand despite PTCy, while nonalloreactive $2 C T C R^{+} T$ cells contract. To confirm that persistence of alloreactive $\mathrm{T}$ cells was not an artifact of $\mathrm{V} \beta 6^{+}, \mathrm{V} \beta 3^{+}$, and ${\mathrm{V} B 5^{+}}^{\mathrm{T}} \mathrm{T}$ cell responses in specific HCT models being superantigen driven, $2 \mathrm{C} \mathrm{TCR}{ }^{+} \mathrm{T}$ cells (39), alloreactive to the major histocompatibility antigen $\mathrm{H} 2 \mathrm{~L}^{\mathrm{d}}$ expressed by B6D2F1 mice, were used. To maintain a reasonably physiologic condition, but still preserve the ability to reliably detect changes in clone frequency with treatment, and since $2 \mathrm{C} \mathrm{TCR}{ }^{+} \mathrm{T}$ cells are nearly all $\mathrm{CD} 8^{+}$, we admixed B6C3F1 2C TCR ${ }^{+} \mathrm{T}$ cells with WT B6C3F1 T cells to manufacture grafts in which approximately $8 \%$ of infused $\mathrm{CD} 8^{+} \mathrm{T}$ cells were $2 \mathrm{C}$ $\mathrm{TCR}^{+}$. In the alloreactive setting (B6D2F1 recipients), $2 \mathrm{C} \mathrm{TCR}^{+} \mathrm{T}$ cells were highly proliferative at days +3 and +7 , and PTCy did not reduce this proliferation (Figure 3, A and B). Rather, despite PTCy on days +3 and $+4,2 \mathrm{C} \mathrm{TCR}{ }^{+} \mathrm{T}$ cell percentages actually increased from day +3 to comprise $35 \%-80 \%$ of CD $8^{+} \mathrm{T}$ cells on day +7 (Figure $3 \mathrm{~B}) .2 \mathrm{C} \mathrm{TCR}^{+} \mathrm{T}$ cells persisted at day +200 and remained highly proliferative (Figure 3C). These results further disprove that alloreactive $\mathrm{T}$ cell elimination is necessary for GVHD prevention by PTCy and reveal that alloreactive $\mathrm{T}$ cell clonal expansion can occur despite PTCy.

To explore the fate of nonalloreactive T cells after PTCy, we used the B6 $\rightarrow$ B6C3F1 MHC-haploidentical model and manufactured analogous grafts in which approximately $8 \%$ of infused $\mathrm{CD} 8^{+}$ T cells were $2 \mathrm{C} \mathrm{TCR}^{+} .2 \mathrm{C} \mathrm{TCR}^{+} \mathrm{T}$ cells, nonalloreactive in this model, maintained low proliferation and a naive phenotype, and consequently contracted by day +7 irrespective of PTCy administration (Figure 3, D-F). Thus, in contrast with the current model (38), the $\mathrm{CD} 8^{+} \mathrm{T}$ cell repertoire surviving PTCy and present early after transplant appears to be dominated by alloreactive $\mathrm{T}$ cells.

Alloreactive $4 C T C R^{+} C D 4^{+} T$ cells also persist after PTCy. Given the differential impact of PTCy on $\mathrm{CD} 4^{+}$versus $\mathrm{CD} 8^{+} \mathrm{T}$ cell proliferation, we further explored the impact of PTCy on alloreactive $\mathrm{CD} 4^{+} \mathrm{T}$ cells by using $\mathrm{T}$ cells expressing the $4 \mathrm{C}$ TCR, which is specific for a widely expressed mouse peptide in the context of I-A ${ }^{\mathrm{d}}(40)$. As B6D2F1 mice express I-A $\mathrm{A}^{\mathrm{d}}, 4 \mathrm{C} \mathrm{TCR}^{+} \mathrm{CD}^{+}$donor T cells are alloreactive in our $\mathrm{B} 6 \mathrm{C} 3 \mathrm{~F} 1 \rightarrow \mathrm{B} 6 \mathrm{D} 2 \mathrm{~F} 1 \mathrm{HCT}$ model, and thus we used an analogous approach to that which we used for $2 \mathrm{C}$ $\mathrm{TCR}^{+} \mathrm{T}$ cells, but here admixed WT and $4 \mathrm{C} \mathrm{TCR}^{+} \mathrm{B} 6 \mathrm{C} 3 \mathrm{~F} 1$ splenocytes in the allograft. PTCy did significantly reduce the proliferation of $4 \mathrm{C} \mathrm{TCR}^{+} \mathrm{CD}^{+} \mathrm{CD} 25-\mathrm{Foxp}^{-} \mathrm{T}$ cells (Figure $4 \mathrm{~A}$ ). Yet $4 \mathrm{C}$ $\mathrm{TCR}^{+} \mathrm{CD} 4^{+} \mathrm{CD} 25^{-} \mathrm{Foxp}^{-} \mathrm{T}$ cells were not eliminated, but rather were found at similar or even significantly higher percentages in PTCy-treated compared with vehicle-treated mice (Figure 4B). These results further confirm that alloreactive $\mathrm{T}$ cells, regardless of their specificity or identity as $\mathrm{CD} 4^{+}$or $\mathrm{CD} 8^{+}$, are not eliminated by PTCy, but rather appear to persist near to or even above percentages observed in mice not treated with PTCy.

Intrathymic clonal deletion is not necessary for GVHD prevention by PTCy. The second of the 3 mechanisms previously proposed to be responsible for PTCy-mediated GVHD prevention is intrathymic clonal deletion of alloreactive $\mathrm{T}$ cell precursors $(20-22,38)$. We tested this hypothesis by using thymectomized recipients in our B6C3F1 $\rightarrow$ B6D2F1 model. PTCy $(25 \mathrm{mg} / \mathrm{kg}$ ) remained high- 
A

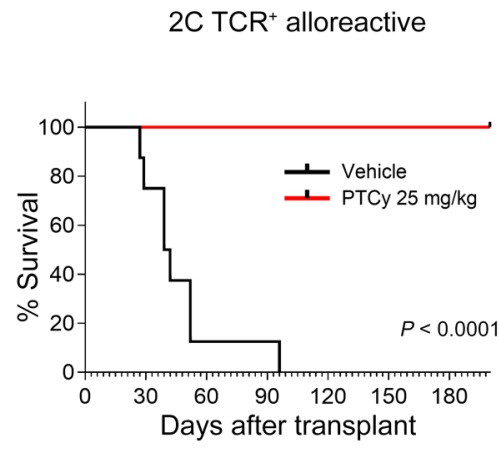

B

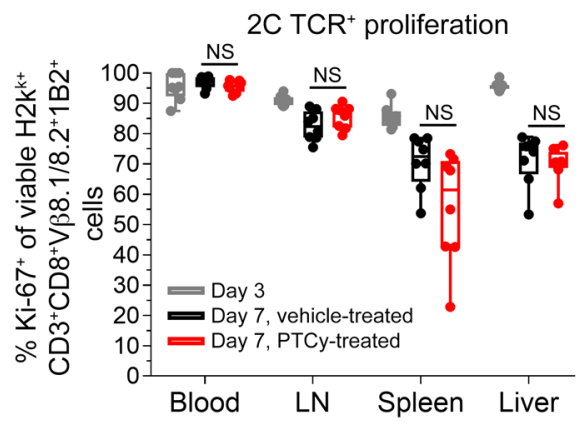

$2 \mathrm{C} \mathrm{TCR}^{+}$alloreactive - day 7

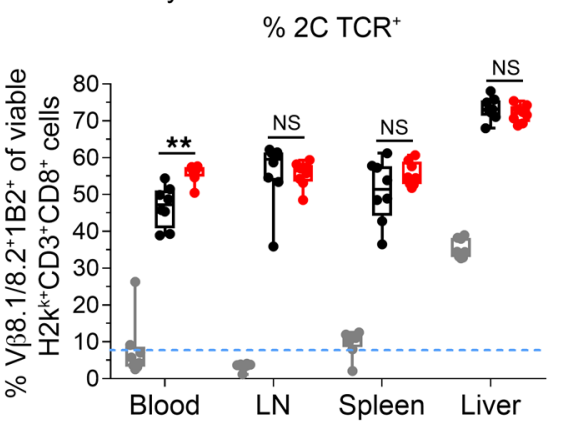

C

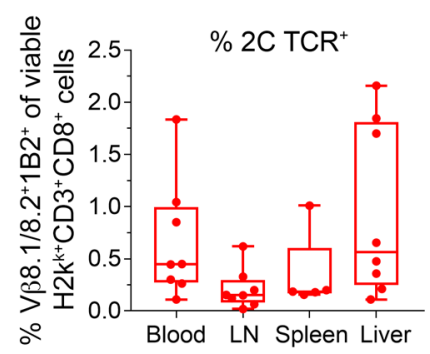

$2 \mathrm{C} \mathrm{TCR}{ }^{+}$alloreactive - day 200

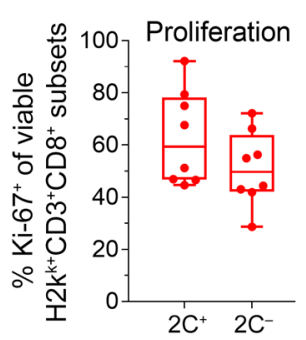

D

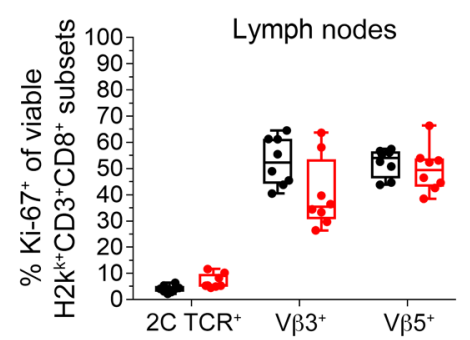

$2 \mathrm{C} \mathrm{TCR}$ non-alloreactive - proliferation at day 7

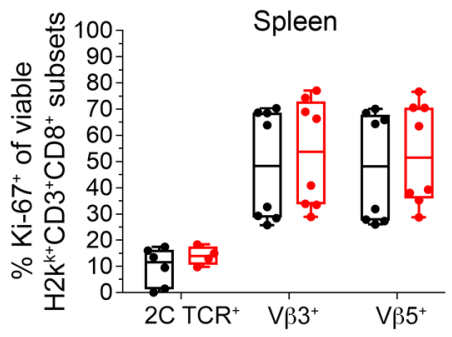

E

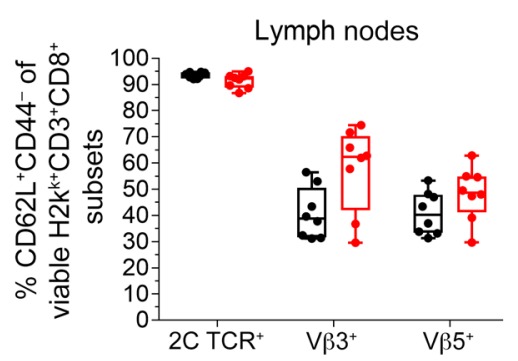

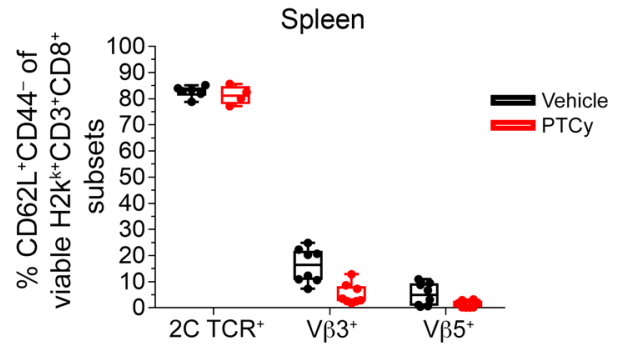

F

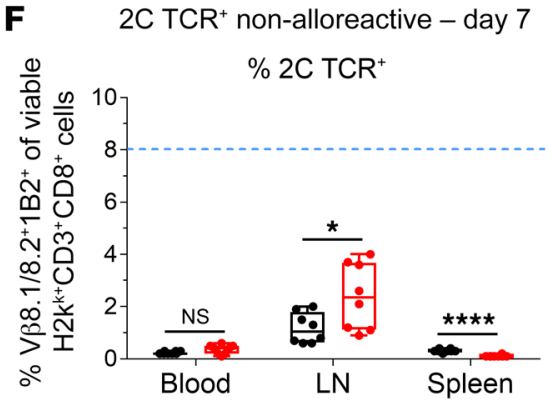

Figure 3. Alloreactive $2 \mathrm{C} \mathrm{TCR}{ }^{+} \mathrm{CD8}^{+} \mathrm{T}$ cells proliferate and preferentially expand despite PTCy, while nonalloreactive $2 \mathrm{C} \mathrm{TCR}^{+} \mathrm{CD8}{ }^{+} \mathrm{T}$ cells remain phenotypically naive, minimally proliferative, and consequently contract. (A-C) Splenocytes from 2 C TCR ${ }^{+}$B6C3F1 transgenic mice were admixed with WT B6C3F1 splenocytes to manufacture grafts in which approximately $8 \%$ (acceptable range $7.2 \%-8.8 \%$ ) of infused CD8 $8^{+} \mathrm{T}_{\text {cells }}$ were $2 \mathrm{C}$ TCR ${ }^{+}$ $\left(\mathrm{V} \beta 8.1 / 8.2^{+} 1 \mathrm{B2}^{+}\right)$and then used as donor splenocytes to transplant mice as shown in Figure 1. (A) GVHD remained universally severe and fatal in vehicle-treated mice, while PTCy remained effective. (B) Left: high-level proliferation (Ki-67+) of 2 C TCR ${ }^{+} \mathrm{T}$ cells was observed in vehicle-treated mice at days +3 and +7 . This proliferation was not reduced by $25 \mathrm{mg} / \mathrm{kg}$ PTCy on days +3 and +4 . Right: 2 C TCR ${ }^{+}$T cells expanded from the $8 \%$ (dotted blue line) percentage in the allograft to dominate the T cell repertoire at day +7 . This relative expansion was not blocked by PTCy on days +3 and +4 . (C) $2 C$ TCR $^{+}$T cells (left) persisted and (right) remained proliferative at day +200 . The proliferation data shown are for the liver. (D-F) An admixed graft approach identical to that used in $\mathbf{A}-\mathbf{C}$ was used, except that the model was B6 $\rightarrow$ B6C3F1. 2C TCR ${ }^{+}$T cells, nonalloreactive in this model, (D) proliferated at low levels, in contrast with alloreactive $\mathrm{V} \beta 3^{+}$and $\mathrm{V} \beta 5^{+} \mathrm{T}$ cells, (E) maintained a naive phenotype, and (F) consequently contracted by day +7 from the $8 \%$ (dotted blue line) percentage in the allograft. Combined results from 2 independent experiments are shown. $n=8 / \mathrm{group} .{ }^{*} P \leq 0.05$; ${ }^{* *} P \leq 0.01 ;{ }^{* * *} P \leq 0.0001$, unpaired $t$ test with Welch's correction for the mice treated with or without PTCy assessed on day +7 .

ly effective; indeed, outcomes were superimposable with results using nonthymectomized recipients (Figure 5), negating a necessary role for the thymus in PTCy-mediated GVHD prevention.

Alloreactive T cells become functionally impaired, but not anergic, after PTCy. Despite alloreactive T cells persisting and even expanding after $25 \mathrm{mg} / \mathrm{kg}$ PTCy, heavily infiltrating a GVHD target organ, and remaining highly proliferative (Figure 2, C-F, Figure 3, B and $\mathrm{C}$, and Figure 6A), minimal histopathologic evidence of GVHD was observed and GVHD-related mortality was abated (Figure 1, A, E, and F). To further test the functional ability of PTCy-treated alloreactive T cells, using our WT B6C3F1 $\rightarrow$ B6D2F1 model, we isolated liver-infiltrating $\mathrm{T}$ cells at day +21 and restimulated them in vitro. Donor T cells from PTCy-treated mice had minimal proliferation in response to self (donor parental) antigen, but proliferated robustly upon reexposure to allogeneic (host parental or third-party $\mathrm{H}_{2} \mathrm{k}^{\mathrm{d}+}$ strain) antigen (Figure 6, B and C, and Supplemental Figure 13). Even so, proliferation of $\mathrm{CD} 8^{+} \mathrm{T}$ cells and production of both Th1 and Th2 cytokines were significantly reduced compared with that in vehicle-treated mice (Figure 6, C and D).

Given the recognized role of $\mathrm{CD} 4^{+} \mathrm{CD} 25^{+} \mathrm{Foxp} 3^{+}$Tregs in GVHD prevention by PTCy $(33,34)$, we repeated these experiments in the absence of $\mathrm{CD} 4^{+} \mathrm{CD} 25^{+} \mathrm{T}$ cells. Despite flow cytometric Treg depletion, reduced proliferation and cytokine production persisted (Figure 6, E and F), suggesting that intrinsic functional 
A

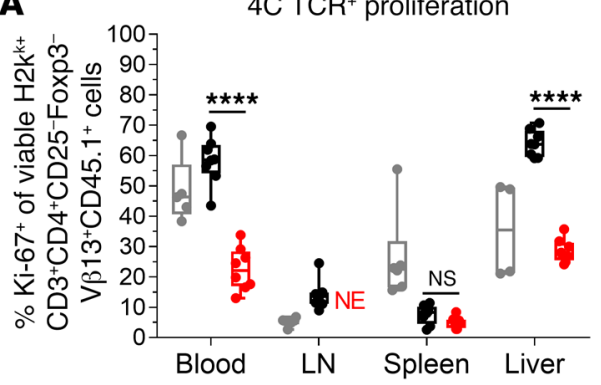

B

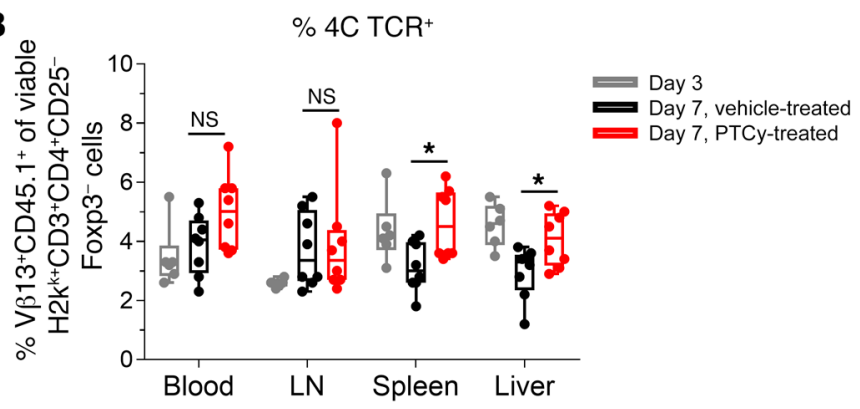

Figure 4. Alloreactive 4C TCR $\mathbf{C D 4}^{+}$T cells persist after PTCy. Splenocytes from 4C TCR+ B6C3F1 (CD45.1+CD45.2+) transgenic mice were admixed with WT B6C3F1 (CD45.1-CD45.2+) splenocytes to manufacture grafts in which approximately $8 \%$ (acceptable range $7.2 \%-8.8 \%$ ) of infused CD4 ${ }^{+} \mathrm{T}$ cells were $4 \mathrm{CTCR}^{+}\left(\mathrm{V} \beta 13^{+} \mathrm{CD} 45.1^{+}\right)$. These splenocytes were then used as donor splenocytes to transplant mice as shown in Figure 1. (A) At day $+7,25$ $\mathrm{mg} / \mathrm{kg} / \mathrm{d}$ PTCy on days +3 and +4 had significantly reduced the proliferation (Ki-67+) of 4C TCR ${ }^{+}$CD4+CD25-Foxp3- $\mathrm{T}$ cells in the blood and liver, which was analogous to its effect on $\mathrm{V} \beta 6^{+} \mathrm{CD} 4^{+} \mathrm{T}$ cells shown in Figure $2 \mathrm{C}$. (B) Nevertheless, $4 \mathrm{C} \mathrm{TCR}^{+} \mathrm{CD} 4^{+} \mathrm{CD} 25^{-}$Foxp3- $\mathrm{T}$ cells persisted at day +7 at similar or even higher percentages compared with levels observed in vehicle-treated mice. Combined results from 2 independent experiments are shown using $n=8$ /group for each of the vehicle-treated and PTCy-treated groups. $n=6$ for mice assessed on day $+3 .{ }^{*} P \leq 0.05$; ${ }^{* * *} P \leq 0.0001$, unpaired $t$ test with Welch's correction for the mice treated with or without PTCy assessed on day +7 . NE indicates that all samples in that subset were not evaluable due to the parent populations all being less than 100 cells.

impairment of alloreactive T cells occurs after PTCy. Even so, donor $\mathrm{T}$ cells did not become functionally anergic after PTCy, retaining the ability to proliferate and produce inflammatory cytokines in response to alloantigen at early and late time points (Figure 6, A and $\left.C^{-} \mathrm{G}\right)$. Furthermore, PTCy did not induce an anergic phenotype in alloreactive T cells (Supplemental Figure 14) (41).

We further tested the intrinsic functionality of PTCy-treated alloreactive $\mathrm{T}$ cells by flow cytometrically sorting viable $2 \mathrm{C} \mathrm{TCR}^{+}$ $\mathrm{T}$ cells on day +5 after vehicle or $25 \mathrm{mg} / \mathrm{kg} / \mathrm{d}$ PTCy on days +3 and +4 and reinfusing these cells into new, irradiated, thymectomized B6D2F1 recipients that did not receive further treatment. While the GVHD induced by the relatively low numbers of $2 \mathrm{C} \mathrm{TCR}^{+} \mathrm{T}$ cells was modest and nonfatal, mice receiving vehicle-treated $2 \mathrm{C} \mathrm{TCR}{ }^{+} \mathrm{T}$ cells had significantly lower weights and worse clinical scores compared with mice receiving PTCy-treated $2 \mathrm{C} \mathrm{TCR}^{+}$ $\mathrm{T}$ cells, whose outcomes were similar to those of mice receiving TCD BM alone (Figure 7 and Supplemental Figure 15). These results further support that PTCy induces intrinsic impaired functional responses of alloreactive $\mathrm{T}$ cells to alloantigen.

$C D 4^{+} \mathrm{CD} 25^{+} \mathrm{Foxp}^{+} \mathrm{T}$ cells, including those that are alloantigen specific, preferentially expand after PTCy. Induction of suppressor T cells is the third putative mechanism of the existing paradigm (20, $24,38)$, and we have previously demonstrated that human (33) and mouse (34) $\mathrm{CD} 4{ }^{+} \mathrm{CD} 25^{+} \mathrm{Foxp} 3^{+} \mathrm{T}$ cells preferentially survive PTCy in vitro. Yet in our B6C3F1 $\rightarrow$ B6D2F1 model, we found that the percentages of $\mathrm{CD} 4^{+} \mathrm{CD} 25^{+} \mathrm{Foxp} 3^{+} \mathrm{T}$ cells as a bulk population were not increased by PTCy at day +7 (Figure 8A), but were similar to or even lower than in vehicle-treated controls. Nevertheless, by day $+21, \mathrm{CD}^{+} \mathrm{CD} 25^{+} \mathrm{Foxp}^{+} \mathrm{T}$ cell percentages were significantly increased in all tested tissue compartments of mice treated with $25 \mathrm{mg} / \mathrm{kg}$ PTCy (Figure 8B). PTCy-treated $\left(25 \mathrm{mg} / \mathrm{kg}\right.$ ) CD $4^{+}$ $\mathrm{CD}^{2} 5^{+} \mathrm{Foxp}^{+} \mathrm{T}$ cells remained largely demethylated within the Treg-specific demethylation region (TSDR) of the Foxp3 gene, suggesting that these were principally natural Tregs (Figure 8C).

Despite continued $\mathrm{T}$ cell, including ${\mathrm{V} \beta 6^{+}}^{+}$conventional $\mathrm{T}$ cell, lymphopenia at day +21 (Figure $2 \mathrm{~B}$ and Supplemental Figure 8), total numbers of $\mathrm{CD}^{+} \mathrm{CD}^{+} 5^{+} \mathrm{Foxp}^{+} \mathrm{T}$ cells in $25 \mathrm{mg} / \mathrm{kg} \mathrm{PTCy}-$ treated mice had recovered to levels similar to or even higher than in vehicle-treated mice at day +21 (Supplemental Figure 16A). Although the $\mathrm{CD} 4^{+} \mathrm{CD} 25^{+} \mathrm{Foxp}^{+} \mathrm{T}$ cell numerical recovery was similar or even more robust after $100 \mathrm{mg} / \mathrm{kg}$ PTCy, the percentages of $\mathrm{CD}^{+} \mathrm{T}$ cells that were $\mathrm{CD} 25^{+} \mathrm{Foxp}^{+}$were blunted in mice treated with $100 \mathrm{mg} / \mathrm{kg}$ PTCy (Figure 8B) due to a disproportionately higher rebound of conventional $\mathrm{CD} 4^{+} \mathrm{CD} 25^{-} \mathrm{Foxp}^{-} \mathrm{T}$ cells (Supplemental Figure 8). This relative imbalance of conventional $\mathrm{T}$ cell versus Treg recovery may contribute to the worse GVHD seen histopathologically in the $100 \mathrm{mg} / \mathrm{kg}$ PTCy treatment group.

Using ${\mathrm{V} \beta 6^{+}}^{+}$as a marker of alloantigen-specific Tregs, we found that mice treated with 25 or $100 \mathrm{mg} / \mathrm{kg}$ PTCy had increased percentages of alloantigen-specific Tregs in the liver at both days +7 and +21 (Figure 8, D and E). As with the numbers of all CD $4{ }^{+} \mathrm{CD} 25^{+}$ Foxp $3^{+} \mathrm{T}$ cells, the total numbers of $\mathrm{V} \beta 6^{+} \mathrm{CD} 4^{+} \mathrm{CD} 25^{+} \mathrm{Foxp}^{+} \mathrm{T}$ cells in mice treated with 25 or $100 \mathrm{mg} / \mathrm{kg}$ PTCy were similar or higher than levels found in vehicle-treated mice (Supplemental Figure $16 \mathrm{~B})$. Furthermore, in the $\mathrm{B} 6 \rightarrow \mathrm{B} 6 \mathrm{D} 2 \mathrm{~F} 1$ and $\mathrm{C} 3 \mathrm{H} \rightarrow \mathrm{B} 6 \mathrm{D} 2 \mathrm{~F} 1 \mathrm{mod}-$ els, the $\mathrm{VB} 6^{+}$percentages of $\mathrm{CD} 4^{+} \mathrm{CD} 25^{+} \mathrm{Foxp}^{+} \mathrm{T}$ cells in the liver at day +7 were similar between vehicle-treated and PTCy-treated mice, whereas the $\mathrm{V} \beta 6^{+}$percentages of $\mathrm{CD}^{+} \mathrm{CD} 25^{-}$Foxp $^{-} \mathrm{T}$ cells were significantly reduced in PTCy-treated mice, resulting in a favorable balance of alloreactive regulatory versus conventional $\mathrm{CD} 4^{+} \mathrm{T}$ cells (Supplemental Figure 9 and Supplemental Figure 10).

Foxp $3^{+}$Tregs play a necessary role that is increasingly important over time. We have previously shown that $\mathrm{CD} 4^{+}$Tregs play a necessary role immediately after transplant in preventing GVHD in xenogeneic and MHC-matched murine HCT models $(33,34)$ and sought to confirm this role in our B6C3F1 $\rightarrow$ B6D2F1 model. A magnetic-column depletion approach only reduced the CD25+ percentage of donor $\mathrm{CD} 4^{+} \mathrm{T}$ cells by approximately $80 \%$ and had minimal impact on transplant outcomes (Supplemental Figure 17). Therefore, we employed a multipronged approach to maximally deplete Foxp $3^{+}$Tregs. Leveraging the presence of the Foxp3 gene on the $\mathrm{X}$ chromosome, male B6C3F1 Foxp3 diphtheria toxin (DT) receptor-expressing mice were used as donors to ensure all Foxp $3^{+}$cells would be susceptible to depletion. DT was adminis- 

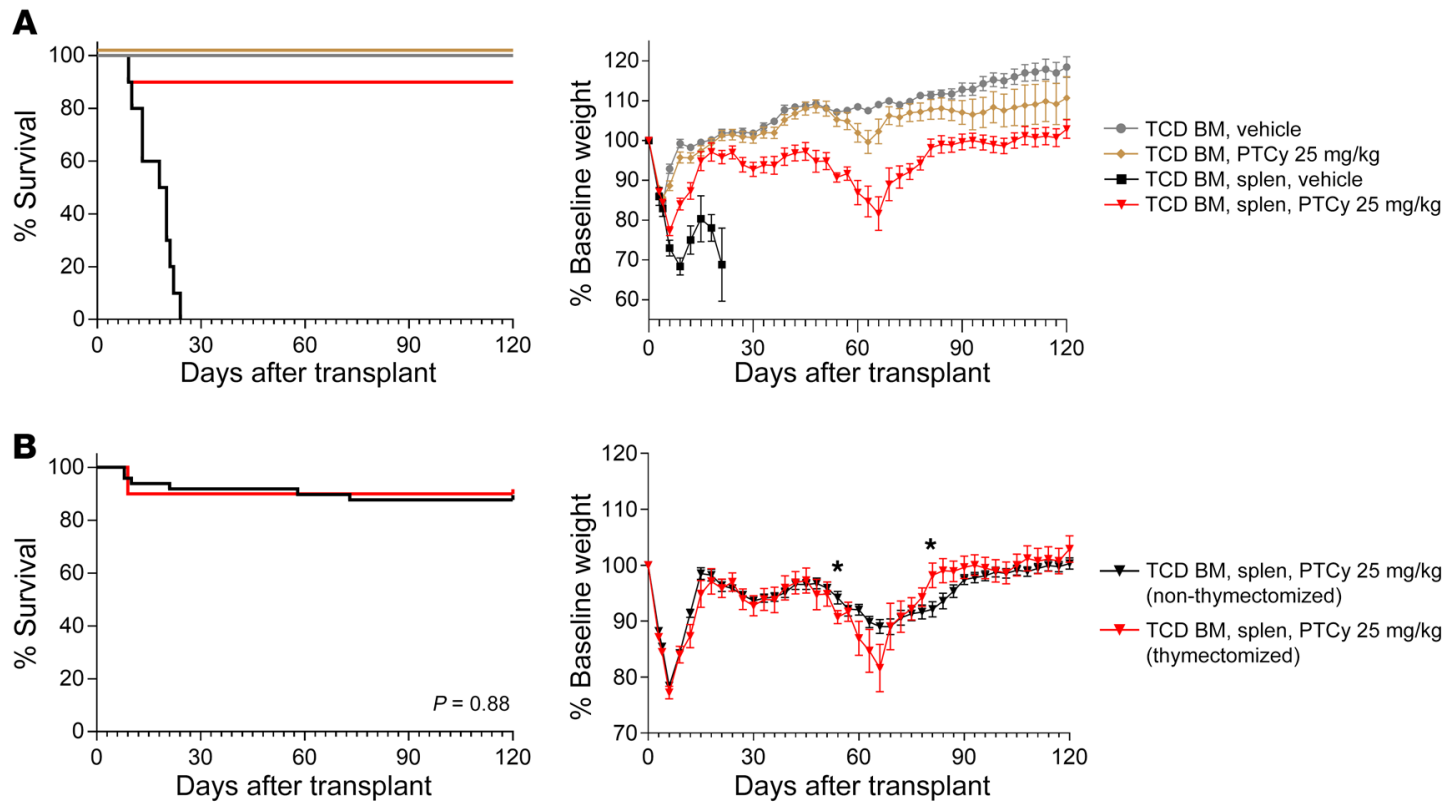

Figure 5. The thymus is dispensable for the efficacy of PTCy in preventing GVHD. (A) Thymectomized recipients were used in the B6C3F1 $\rightarrow$ B6D2F1 model. PTCy remained effective. Combined results of 2 independent experiments are shown. $n=5$ mice/group/experiment. (B) Data from nonthymectomized recipients (10 experiments, $n=49$ ) are overlaid on results from $\mathbf{A}(n=10)$; the outcomes were nearly identical. Survival was compared using the exact log-rank test. ${ }^{*} P<0.05$ on point-wise comparison using Wilcoxon's rank sum test.

tered for 2 consecutive days at $25 \mu \mathrm{g} / \mathrm{kg} / \mathrm{d}$ and then again 6 days later for 2 more consecutive days to overcome the Treg rebound seen approximately 7 days after depletion using this system (42). Thymectomized recipients were used to nullify any potential confounding effect of new Treg maturation in the thymus. This approach provided a greater than $2-\log \mathrm{CD} 4^{+} \mathrm{Foxp}^{+}$depletion to less than $0.1 \%$ of $\mathrm{CD}^{+}$splenocytes on day +10 . Foxp $3^{+}$depletion immediately after transplant in PTCy-treated mice resulted in severe GVHD clinically and histopathologically that was fatal in a subset of mice and was only partially attenuated with eventual recovery of Tregs to normal levels (Figure 9A, Supplemental Figure 18, and Supplemental Figure 19).

It is unknown whether Tregs are only critical for PTCymediated GVHD prevention immediately after transplant $(33,34)$ or whether their continued presence is necessary to maintain tolerance. Selective depletion of Foxp ${ }^{+} \mathrm{T}$ cells at defined posttransplant time points (day $+30,+60$, or +150 ) also resulted in severe GVHD clinically and histopathologically (Figure 9, B and C, Supplemental Figure 18, and Supplemental Figure 19). In fact, the rapidity, severity, and lethality of the induced GVHD were more pronounced when Tregs were depleted at later time points.

$\mathrm{CD}^{+}{ }^{+}$Tregs given 4 days prior to conventional $\mathrm{T}$ cells can effectively prevent GVHD for MHC-matched murine HCT or (at high Treg/effector $\mathrm{T}$ cell ratios) TCD HLA-haploidentical HCT $(43,44)$. However, in our B6C3F1 $\rightarrow$ B6D2F1 model, severe and fatal GVHD still resulted when $\mathrm{CD} 4^{+}$Tregs were given at physiologic or supraphysiologic doses 4 days prior to T cell-replete transplant (Supplemental Figure 20), suggesting that Foxp $3^{+}$Tregs, while necessary, are not sufficient to prevent severe GVHD in T cell-replete MHC-haploidentical HCT.

Highly active suppressive mechanisms are induced immediately after PTCy. We further tested the importance of suppressive mech- anisms for PTCy-mediated GVHD prevention by taking previously transplanted nonthymectomized mice and reinfusing them with 40 or $120 \times 10^{6}$ splenocytes from new PTCy-nonexposed donors at specific time points. Regardless of time point, mice initially transplanted with TCD BM without PTCy developed severe, frequently fatal GVHD after splenocyte reinfusion (Figure 10, $\mathrm{A}^{-} \mathrm{C}$, and Supplemental Figure 21). Conversely, mice transplanted initially with TCD BM, splenocytes, and $25 \mathrm{mg} / \mathrm{kg}$ PTCy all survived and even steadily gained weight after reinfusion at 4 to 5 months after transplant (Figure 10A and Supplemental Figure 21A). Similar findings were seen in thymectomized mice (Supplemental Figure 21B). We next assessed how early these suppressive mechanisms were induced. Mice transplanted with splenocytes and PTCy that received splenocyte reinfusion either on day +28 (Figure 10B) or even day +5 ( 24 hours after the last cyclophosphamide dose) (Figure 10C) did not develop GVHD and were indistinguishable from PTCy-treated mice reinfused with vehicle. Importantly, intraperitoneally administered cyclophosphamide has a short half-life of approximately 30 minutes in mice and is undetectable in the blood after 3 to 4 hours (45). These data suggest that PTCy rapidly induces suppressive mechanisms that are sufficient to prevent GVHD induction by alloreactive T cells not exposed to cyclophosphamide.

\section{Discussion}

Our data conclusively show in 5 HCT models that alloreactive T cells are not eliminated after PTCy-based murine HCT regardless of PTCy dose, degree of MHC-matching, or specificity of alloreactive cell; indeed, alloreactive $\mathrm{T}$ cells remained near or frequently above donor percentages. Although not eliminated, $\mathrm{CD}^{+}$alloreactive T cells had reduced proliferation shortly after PTCy and, consequently, their early expansion was constrained. Furthermore, $\mathrm{CD}^{+}$and $\mathrm{CD}^{+}$alloreactive $\mathrm{T}$ cells became functionally impaired 
A

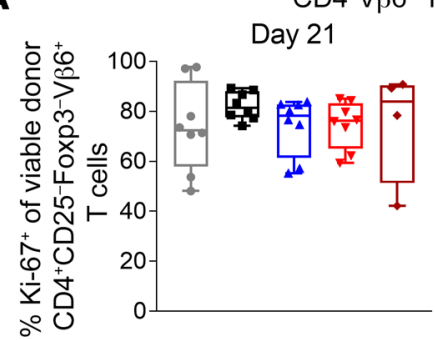

$\mathrm{CD} 4^{+} \vee \beta 6^{+} \mathrm{T}_{\text {con }}$ proliferation
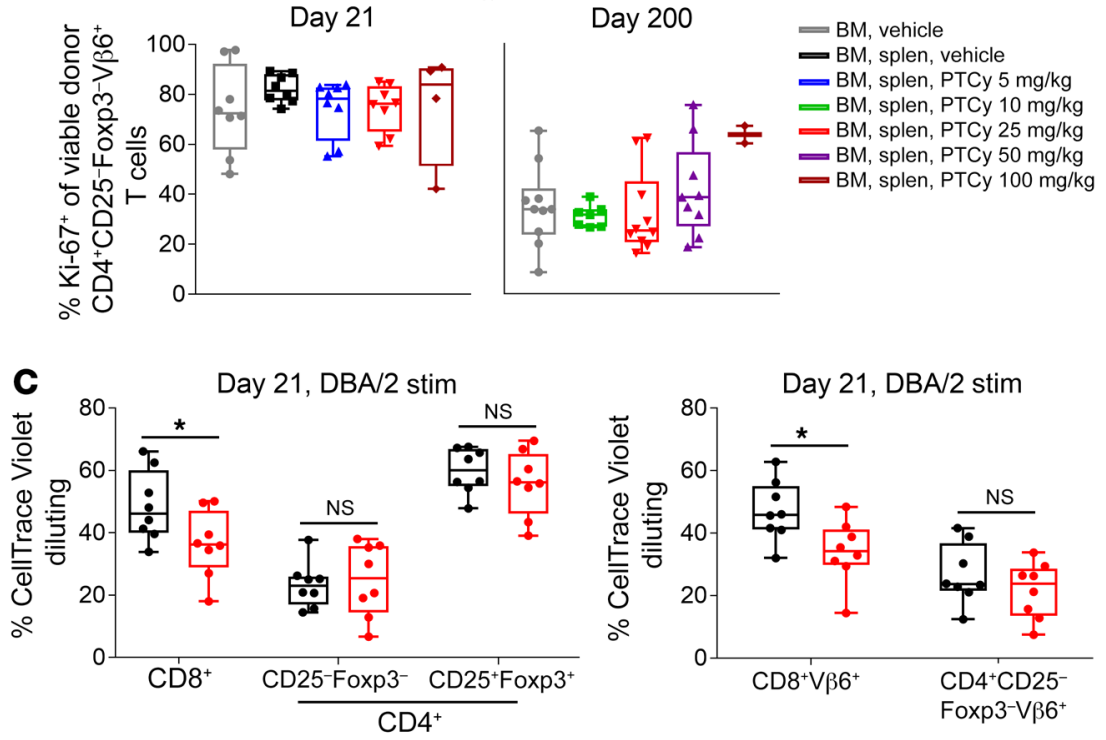

D

Day 21 , C3H stim

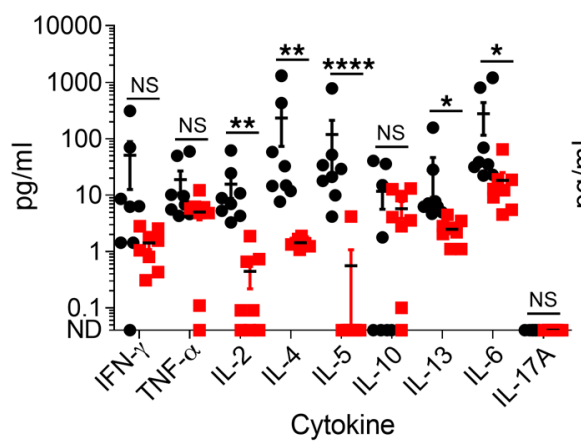

G

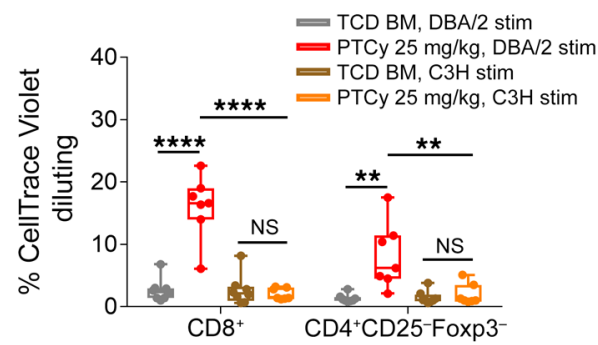

Day 21, DBA/2 stim

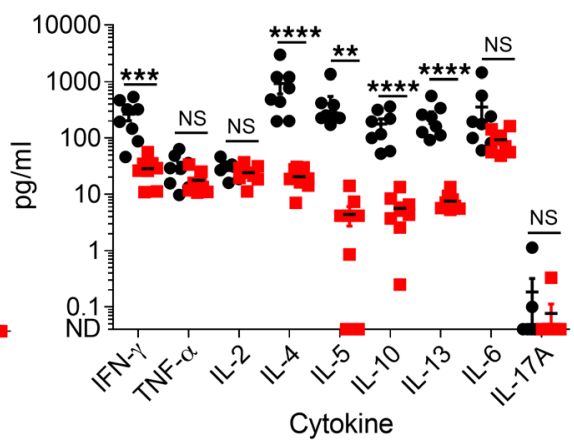

Day 150, C3H stim

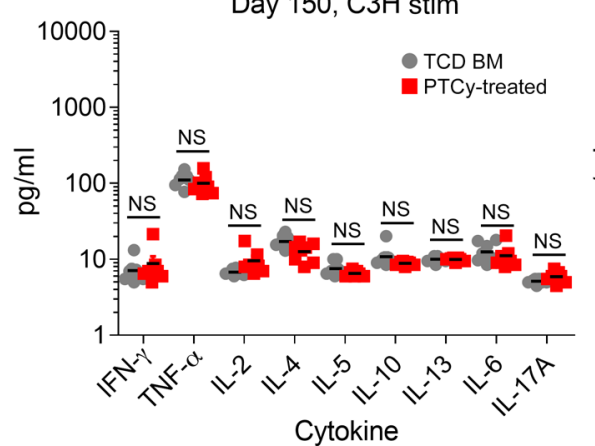

B

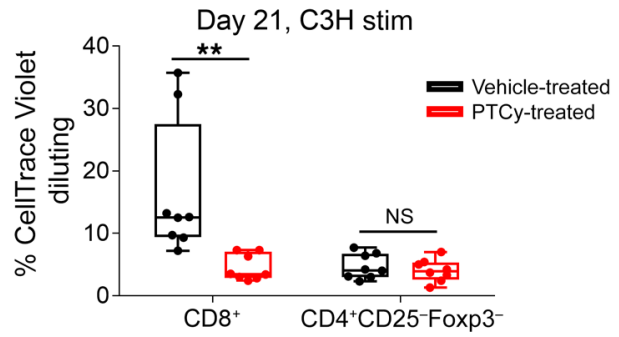

E Day 21, no Tregs, DBA/2 stim

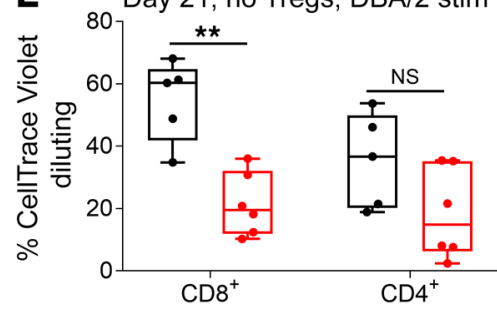

F Day 21, no Tregs, DBA/2 stim

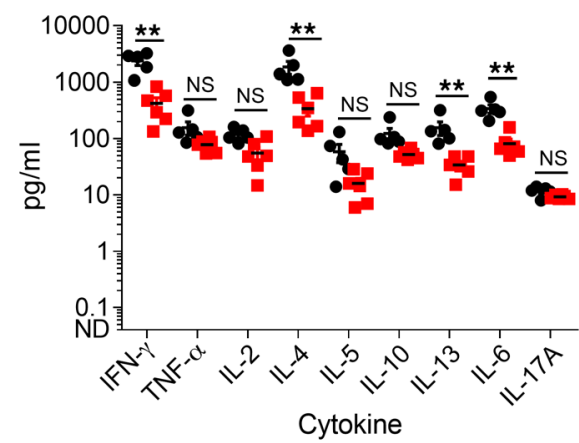

Day 150, DBA/2 stim

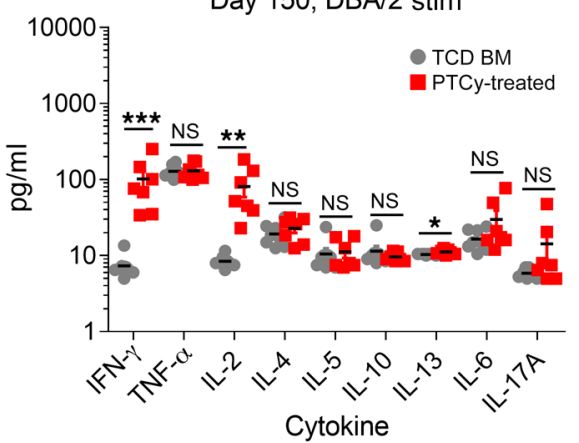

Figure 6. PTCy-treated alloreactive T cells become functionally impaired, but not anergic, in response to alloantigen. Transplantation was performed as in Figure 1. PTCy was $25 \mathrm{mg} / \mathrm{kg} / \mathrm{d}$ on days +3 and +4 where not otherwise specified. (A) High-level proliferation (Ki-67+) of liver-infil-

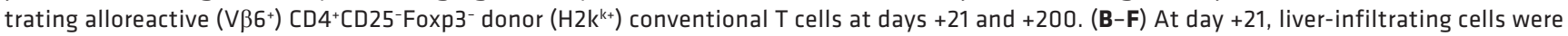
isolated and restimulated (stim) in vitro with irradiated (30 Gy) donor-parental (C3H) or host-parental (DBA/2) splenocytes at $2 \times 10^{5}$ each of donors and stimulators per well. (B) Donor $\left(\mathrm{H}_{2} \mathrm{k}^{\mathrm{k}+} \mathrm{H}_{2} \mathrm{k}^{\mathrm{b}+}\right) \mathrm{T}$ cells from PTCy-treated mice had low proliferation to $\mathrm{C} 3 \mathrm{H}$ at 5 days. (C) Proliferation was robust to alloantigen (DBA/2), although CD8+ T cell proliferation was reduced. (D) Cytokine production at 24 hours to alloantigen by PTCy-treated cells was markedly lower. (E and $\mathbf{F}$ ) Procedures similar to those shown in B-D were followed, except responder T cells were flow cytometrically purified including removing $C D 4^{+} \mathrm{CD} 25^{+} \mathrm{T}$ cells (Tregs) prior to coculture. Similarly impaired (E) proliferation and (F) cytokine production by PTCy-treated T cells were seen. (G) The procedures in B-D were repeated at day +150 . PTCy-treated T cells continued to proliferate and produce IFN- $\gamma$ and IL-2 in response to alloantigen but not self-antigen; these differences were not due to disparities in the CD4+CD25+Foxp3 ${ }^{+}{ }^{+}$cell content of the restimulated cells $(P=0.21$; not shown). Combined results from 2 independent experiments are shown for all parts. $n=8$ mice/group for all parts except the $100 \mathrm{mg} / \mathrm{kg}$ PTCy group shown in the left panel in $\mathbf{A}(n=5)$, the right panel in $\mathbf{A}$ (which shows all mice from Figure $1 \mathbf{A}$ surviving to day 200), E-F ( $n=5$-6/group), and the $25 \mathrm{mg} / \mathrm{kg}$ PTCy groups in G $(n=7)$. ${ }^{*} P \leq 0.05 ;{ }^{* *} P \leq 0.01$; ${ }^{* * *} P \leq 0.001 ;{ }^{* * * *} P \leq 0.0001$, unpaired $t$ test with Welch's correction. ND, not detectable. Statistical testing of cytokines was adjusted for multiple comparisons by the Holm-Šidák method. 
A

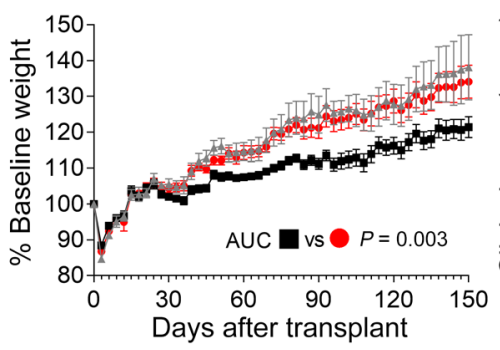

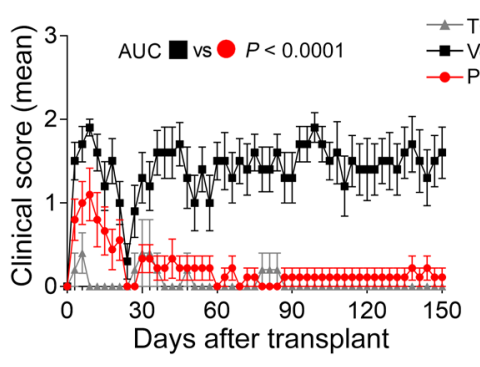

B $\quad 2 \mathrm{CTCR}+\mathrm{T}$ cells infiltrating the liver

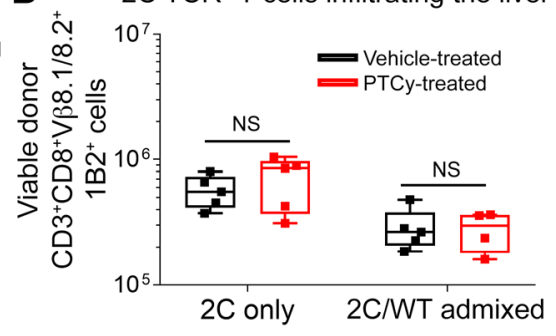

Figure 7. PTCy-treated alloreactive T cells have impaired intrinsic ability to induce GVHD on serial transplant. Irradiated B6D2F1 recipient mice were transplanted with $40 \times 10^{6} 2 \mathrm{C} \mathrm{TCR}{ }^{+}$admixed B6C3F1 splenocytes and $10 \times 10^{6}$ WT TCD BM cells as described in Figure 3 ( $8 \%$ of CD8 ${ }^{+}$T cells were $2 \mathrm{C} \mathrm{TCR}{ }^{+}$) or with $40 \times 10^{6}$ splenocytes and $10 \times 10^{6}$ TCD BM from 2 C TCR ${ }^{+}$B6C3F1 donors. Mice received either vehicle or 25 mg/kg/d PTCy on days +3 and +4 . On day +5 , splenocytes from these mice were flow cytometrically sorted to isolate viable $2 C$ TCR ${ }^{+} T$ cells $\left(L_{I V E} / D E A D^{-} C D 8^{+} V \beta 8.1 / 8.2^{+} 1 B 2^{+}\right.$) $0.5 \times 10^{6} 2 \mathrm{C} \mathrm{TCR}+\mathrm{T}$ cells from mice that had received $2 \mathrm{C} / \mathrm{WT}$ admixed grafts or $1 \times 10^{6} 2 \mathrm{C}$ TCR ${ }^{+} \mathrm{T}$ cells from mice that had received only $2 \mathrm{C}$ splenocytes were combined with $5 \times 10^{6} 2$ C TCD BM cells (BM from new 2 C donors that was flow cytometrically depleted of Thy1.2+ cells). These grafts then were transplanted into new, irradiated (10.5 Gy), thymectomized, B6D2F1 recipients. These recipients did not receive any posttransplant treatment (i.e., no PTCy or vehicle on days $+3 /+4)$. Combined results from mice receiving $2 C \mathrm{TCR}^{+} \mathrm{T}$ cells from $2 \mathrm{C}$ only grafts $(n=5$ vehicle treated, $n=5$ PTCy treated) or from 2C/WT admixed grafts ( $n=5$ vehicle treated, $n=4$ PTCy treated) are shown as are data for 5 mice receiving TCD BM only. Results of each individual experiment are shown in Supplemental Figure 15. (A) Although the GVHD induced was not fatal for either treatment group, mice receiving PTCy-treated cells had superior weights and clinical scores compared with mice receiving vehicle-treated cells. AUC values were compared using Wilcoxon's rank sum test. (B) These differences were seen even though similar numbers of $2 C$ TCR+ T cells persisted in the liver at day +150 in mice receiving vehicle-treated or PTCy-treated cells.

in terms of their ability to cause clinical GVHD and to proliferate and elaborate inflammatory cytokines in vitro in response to alloantigen restimulation. This functional impairment is at least partially reversible, as Foxp3 ${ }^{+}$depletion resulted in severe clinical and histopathologic GVHD, consistent with our prior studies $(33,34)$. Yet our current work revealed additional insights showing that the necessary role of Foxp $3^{+}$Tregs in restraining alloreactive $\mathrm{T}$ cells surviving PTCy is increasingly critical over time and that alloantigen-specific Tregs preferentially persist after PTCy. Moreover, we found that suppressive mechanisms are induced immediately after PTCy and are sufficient to control PTCy-nonexposed alloreactive $\mathrm{T}$ cells infused as early as day +5 .

Further study is needed to determine to what extent our mechanistic findings are conserved in human HCT using PTCy. This is particularly true given that our murine models rely on splenocytes as the source of T cells to initiate GVHD, which is distinct from human HCT where T cell-replete BM or peripheral blood are the source of T cells. Furthermore, PTCy is often used clinically in combination with other immunosuppressants (2), particularly in the HLA-haploidentical HCT setting, and these other immunosuppressants can interact with PTCy in terms of the effects on immune subset survival and reconstitution $(33,46)$. Even so, given that PTCy remains effective at preventing chronic GVHD when used alone or in combination with other immunosuppressants (2, 46), it is likely that the effects of PTCy itself are dominant and not blocked by the integration of these other agents.

Importantly, supporting the possible direct clinical relevance of our findings, our results appear fully consistent with clinical outcomes. In human HCT, grade II acute GVHD frequently occurs after PTCy $(2,5,30-32)$ and even may be associated with better malignancy control $(5,47)$. Furthermore, high rates of severe acute GVHD are seen when PTCy is used as single-agent GVHD prophylaxis after peripheral blood HLA-matched HCT $(48,49)$. These findings strongly support that alloreactive $\mathrm{T}$ cells are not eliminated by PTCy in patients and can mediate clinically significant GVHD and/or graft-versus-tumor immunity. Furthermore, in skin-allografting models, tolerance was maintained even if intrathymic clonal deletion broke down at later stages (20), challenging the necessity of the thymus for PTCy-mediated GVHD prevention. Indeed, in human HCT, PTCy remains effective in older adults and/or those treated with myeloablative conditioning in whom residual thymic function may be limited or absent $(2,29)$

The current model (38) for understanding how PTCy prevents GVHD largely was extrapolated from skin-allografting models that were highly contextual in their efficacy (25-27). Using an identical dose $(200 \mathrm{mg} / \mathrm{kg})$ and timing $($ day +3$)$ of PTCy in the same $\mathrm{C} 3 \mathrm{H} / \mathrm{AKR} \mathrm{MHC}$-matched model, we did show a reduction in $\mathrm{V} \beta 6^{+}$ $\mathrm{T}$ cell percentages compared with those in vehicle-treated mice, and this reduction was more pronounced with higher PTCy doses (Supplemental Figure 11); however, the percentages remained near or above donor levels. Differences in these results may reflect a difference in graft-versus-host compared with host-versus-graft immunity, peculiarities of mixed chimeric states, and/or insufficient splenocyte dose; $100 \times 10^{6}$ splenocytes were required in the skin-allografting models to successfully induce tolerance, and lower cell doses could lead to accelerated rejection $(25,26)$. The use of radiation is unlikely to be a contributing factor, as we actually observed increased $\mathrm{V} \beta 6^{+} \mathrm{T}$ cell percentages after PTCy in nonirradiated mice in our B6 $\rightarrow$ B6D2F1 model (Supplemental Figure 9). Importantly, alloreactive $\mathrm{T}$ cell clonal deletion can occur through peripheral tolerance mechanisms independent of PTCy, as demonstrated in thymectomized recipients of TCD BM not treated with PTCy in which the percentages of both $\mathrm{CD} 4^{+} \mathrm{V} \beta 6^{+}$and $\mathrm{CD} 8^{+} \mathrm{V} \beta 6^{+}$ $\mathrm{T}$ cells were significantly reduced (Supplemental Figure 19). Thus, alloreactive $\mathrm{T}$ cell depletion seen in specific contexts in skinallografting models does not necessarily imply direct elimination by PTCy. Indeed, the depletion seen in those mixed chimeric models occurred progressively over several weeks, and the percentages 
A

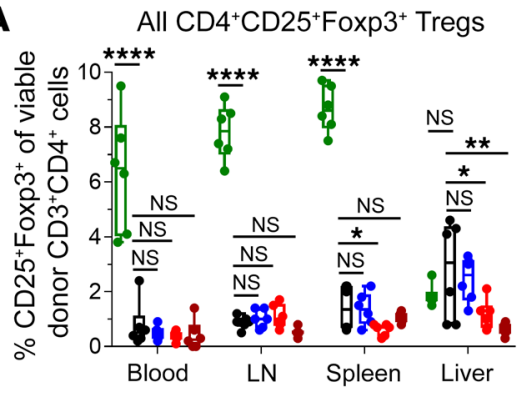

B

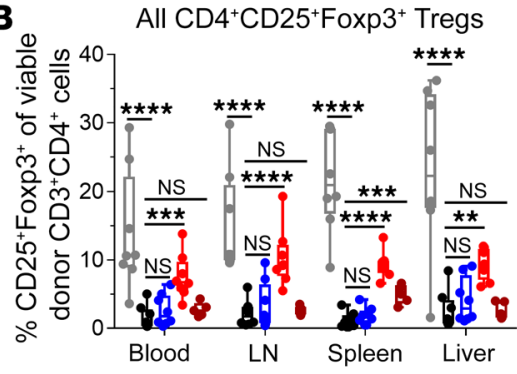

Day 7

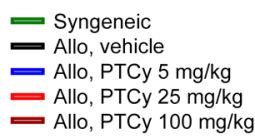

D

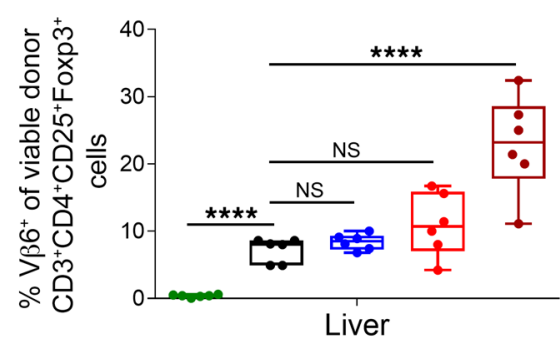

Day 21

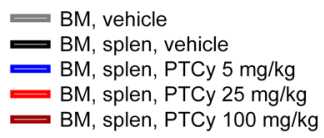

E

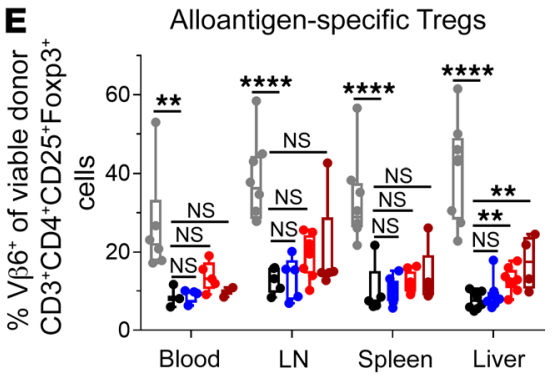

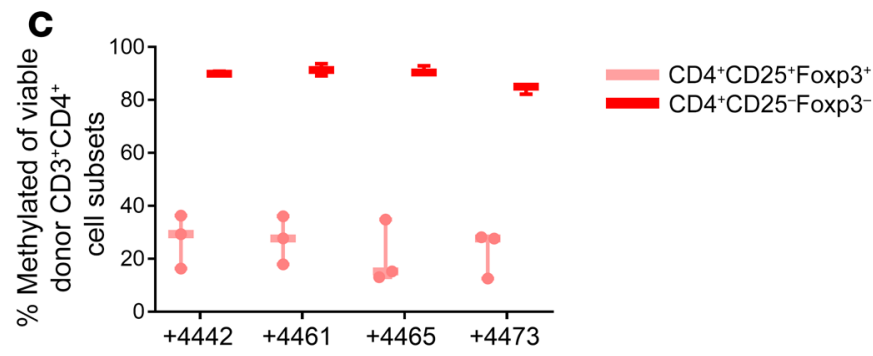

Figure 8. CD4 ${ }^{+} \mathrm{CD}^{2} 5^{+} \mathrm{Foxp}^{+}$Tregs, including alloantigen-specific Tregs, preferentially expand after optimally dosed PTCy. Mice were transplanted as in Figure 2. For C, allografts were made using Foxp3-DTR-GFP-expressing B6C3F1 male donor mice. (A) At day +7 in the B6C3F1 $\rightarrow$ B6D2F1 HCT model, Treg percentages were stable to slightly decreased after PTCy treatment. (B) However, at day +21 , mice treated with 25 mg/kg PTCy had significantly higher percentages of CD4+CD25+Foxp3 ${ }^{+}$Tregs in all tissue compartments. This increase was blunted after $100 \mathrm{mg} / \mathrm{kg}$ PTCy, a dose associated with worse GVHD histopathologically. (C) At day $+21, C D 25^{+}$Foxp3(GFP) ${ }^{+} C D 4^{+}$T cells pooled from the liver, blood, peripheral lymph nodes, and spleens of mice $(n=3)$ treated with $25 \mathrm{mg} / \mathrm{kg} / \mathrm{d}$ PTCy on days +3 and +4 were largely demethylated within the TSDR of the Foxp3 gene, suggesting that the CD4 ${ }^{+} \mathrm{CD}_{25}{ }^{+} \mathrm{Foxp3}^{+} \mathrm{T}$ cell population expanded after PTCy was primarily composed of natural Tregs. In contrast, CD25-Foxp3(GFP)- CD4 ${ }^{+}$ $T$ cells at day +21 from these same mice were nearly all methylated. The numbers indicate the CpG site location relative to the transcriptional start site. (D-E) The percentages of alloantigen-specific $\left(V \beta 6^{+}\right)$Tregs in the liver increased after PTCy at both days (D) +7 and $(\mathbf{E})+21$. Of note, all samples in the day $+7100 \mathrm{mg} / \mathrm{kg}$ PTCy group had Treg numbers of less than 100 cells and would therefore normally be excluded, but are included here for illustrative purposes. Combined results from (A, D) 3 ( $n=6 /$ group) or (B, E) 2 ( $n=8 /$ group except $100 \mathrm{mg} / \mathrm{kg}$ PTCy; $n=5)$ independent experiments are shown. ${ }^{*} P \leq 0.05 ;{ }^{* *} P \leq 0.01 ;{ }^{* *} P \leq 0.001 ;{ }^{* * *} P \leq 0.0001$, 1-way ANOVA with Holm-Šidák post hoc test using the allogeneic (Allo) TCD BM and splenocyte, vehicle group (labeled Allo, vehicle for $\mathbf{A}, \mathbf{D}$ and BM, splen, vehicle for $\mathbf{B}, \mathbf{E}$ ) as control.

were reduced only in half at 2 weeks after PTCy (21), suggesting that the observed effect was not solely a result of immediate killing by PTCy. Furthermore, PTCy did not eliminate alloreactive T cells in MHC-mismatched skin-allografting models (21), consistent with our data. Moreover, donor $\mathrm{T}$ cells continue to proliferate, although to a lower degree, despite PTCy treatment after MHCmatched HCT (35), which is also consistent with our results. Overall, even if alloreactive T cell depletion may occur after PTCy in very specific contexts, this depletion absolutely is not required for PTCy to effectively prevent severe GVHD, as shown in our several HCT models, consistent with recent findings of the persistence of self-reactive T cells in autologous tolerant states $(50,51)$.

Our data support a 2-part mechanism of GVHD attenuation by PTCy involving direct effects both on alloreactive T cells themselves and on suppressive cell populations that control GVHD. T cells whose functional alloreactivity is inadequately restrained by PTCy may cause GVHD. This effect may be exacerbated in the setting of lower Treg levels (Supplemental Figure 18) or when Tregs are removed (Figure 9) $(33,34)$, confirming that Tregs after PTCy retain functional suppressive capability in vivo. The Tregs surviving and reconstituting after PTCy in this and our prior studies appear to be chiefly natural Tregs, and in our prior studies, we showed that they also retain suppressive function in vitro $(33,34)$. Alloreactivity persisting despite PTCy generally is controlled prior to progression to severe acute GVHD, which may be associated with a compensatory increase in Tregs in PTCy-treated patients (33). The necessary role for Tregs that is increasingly important over time after transplant in our $\mathrm{B} 6 \mathrm{C} 3 \mathrm{~F} 1 \rightarrow \mathrm{B} 6 \mathrm{D} 2 \mathrm{~F} 1$ model may explain clinical chronic GVHD prevention by PTCy; this hypothesis is supported by the amelioration of clinical chronic GVHD manifestations with Treg expansion by IL-2 (52). Although the contribution of $\mathrm{CD}^{+}{ }^{+} \mathrm{Foxp}^{+}$Tregs $(53,54)$ to PTCy-mediated 
A

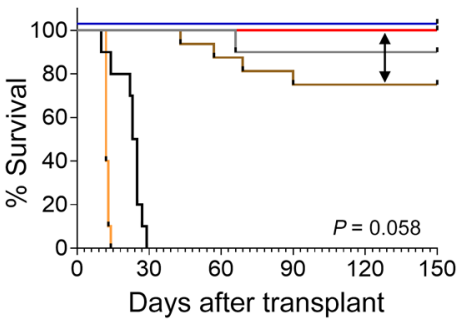

B
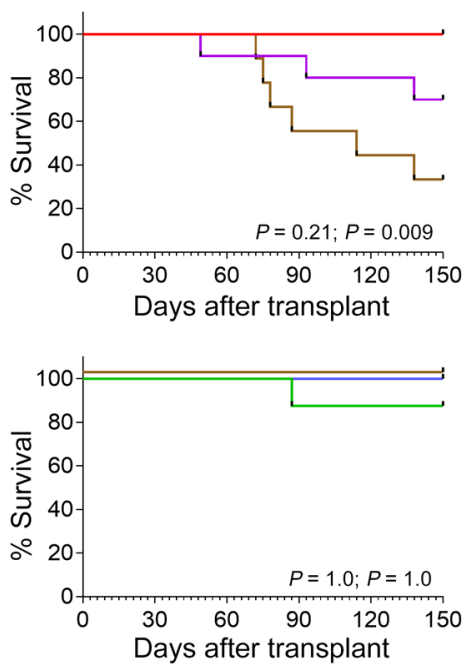

C

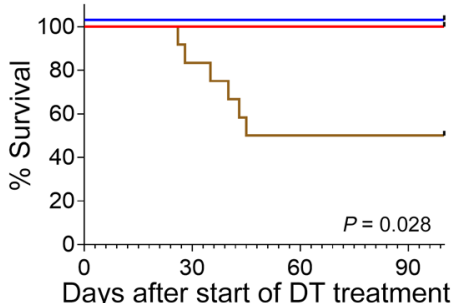

Treg depletion day 0

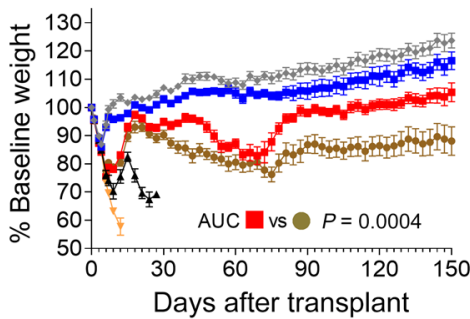

Treg depletion day 30 or 60
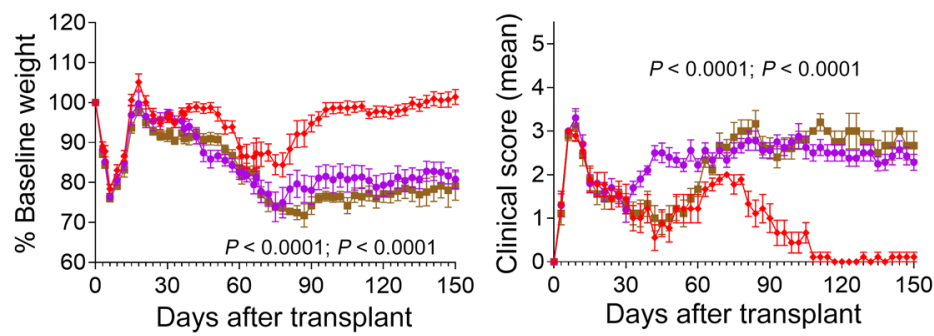

DTR BM, DTR splen, PTCy

$\rightarrow-$ Vehicle

$\longrightarrow$ DT $d+30,+31,+36,+37$

$\rightarrow$ DT $d+60,+61,+66,+67$

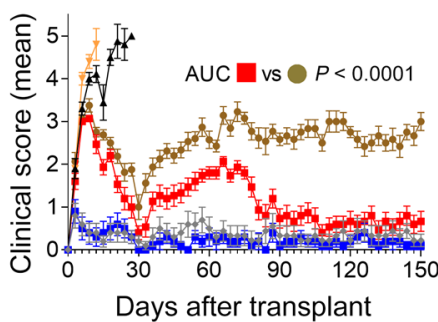

$\because$ DTR BM, vehicle $\rightarrow$ WT BM, PTCy, DT -DTR BM/splen, vehicle DTR BM/splen, DT - DTR BM/splen, PTCy
- - DTR BM/splen, PTCy, DT

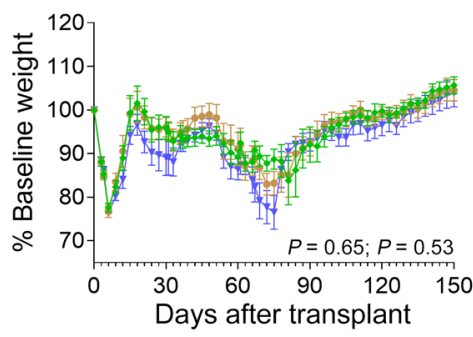

Treg depletion day 150

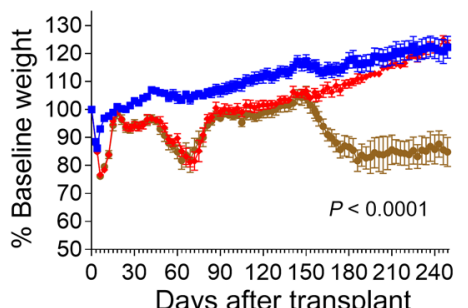

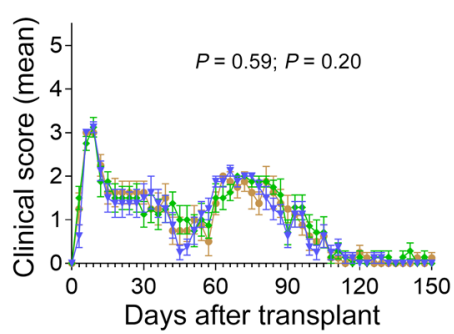

WT BM, WT splen, PTCy

$\rightarrow$-Vehicle

- DT d +30, +31, +36, +37

- DT d +60, +61, +66, +67

Figure 9. Foxp3+ depletion induces severe and fatal GVHD, particularly at later posttransplant time points. DT treatment of thymectomized B6D2F1 mice transplanted with Foxp3-DTR-expressing B6C3F1 grafts from 9- to 13-week-old male donors beginning (A) immediately after transplant (days $0,+1,+6,+7$ ), (B) at day +30 (days $+30,+31,+36,+37$ ) or day +60 (days $+60,+61,+66,+67$ ), or (C) at day +150 (days $+150,+151,+156$, $+157)$ induced severe and frequently fatal CVHD. Survival was compared using the exact log-rank test. AUCs were compared using Wilcoxon's rank sum test. $P$ values for B reflect comparisons of vehicle with DT day +30 (over days +30 to +150 ) or day +60 (over days +60 to +150 ), respectively. Weights and clinical scores in C were compared between the 2 DTR groups over days +150 to +250 . Combined results from (A-B) 2 or (C) 4 independent experiments are shown. $n=10-16 /$ group for $\mathbf{A} ; n=9-10 /$ DTR group and $n=8 /$ WT group for $\mathbf{B}$; and $n=15,9$, and 12/group for the WT, DTR/vehicle, and DTR/DT groups, respectively, for $\mathbf{C}$.

GVHD prevention is unknown and these cells would be eliminated with Foxp3 depletion in our studies (34), CD8 ${ }^{+}$Foxp $3^{+} \mathrm{T}$ cells were a minor population and their levels did not correlate with clinical outcome or treatment in our model (Supplemental Figure 18 and Supplemental Figure 22). Furthermore, our prior data have suggested a dominant role for $\mathrm{CD} 4^{+}$Tregs $(33,34)$.

Overall, the exact nature of the alloreactive $\mathrm{T}$ cell functional impairment induced by PTCy and the operating mechanisms of regulation mediated by $\mathrm{CD} 4^{+}$Tregs and perhaps other suppressive populations in preventing or controlling GVHD after PTCy require further study and are ongoing areas of investigation in our labora- tory. T cell dysfunction can occur via several mechanisms, including tolerance, anergy, ignorance, senescence, and exhaustion (55). We have shown that central or peripheral deletional tolerance does not occur after PTCy in our models. Peripheral tolerance can occur through active suppression by Tregs, which we have shown to play a role. However, $2 \mathrm{C} \mathrm{TCR}^{+} \mathrm{T}$ cells removed from the suppressive environment retained functional impairment in vivo (Figure 7) and alloreactive $\mathrm{T}$ cells in Treg-depleted mixed lymphocyte cultures retained deficits in proliferation and inflammatory cytokine production (Figure 6), suggesting this is not the only operating mechanism. We have shown that PTCy-treated allore- 
A

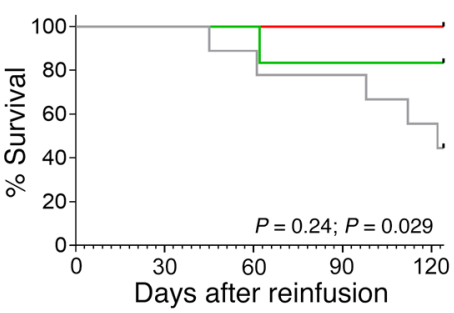

B
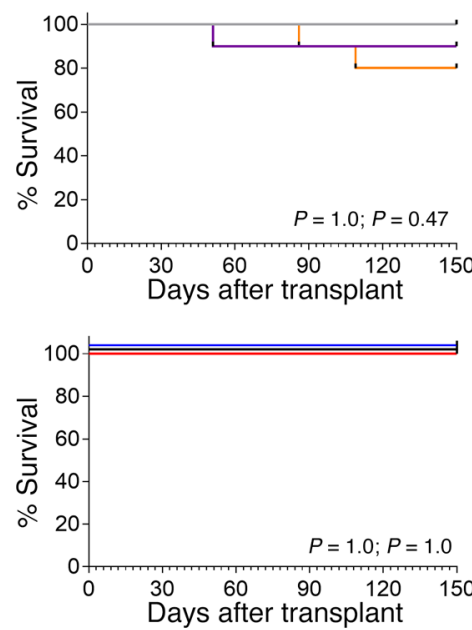

C
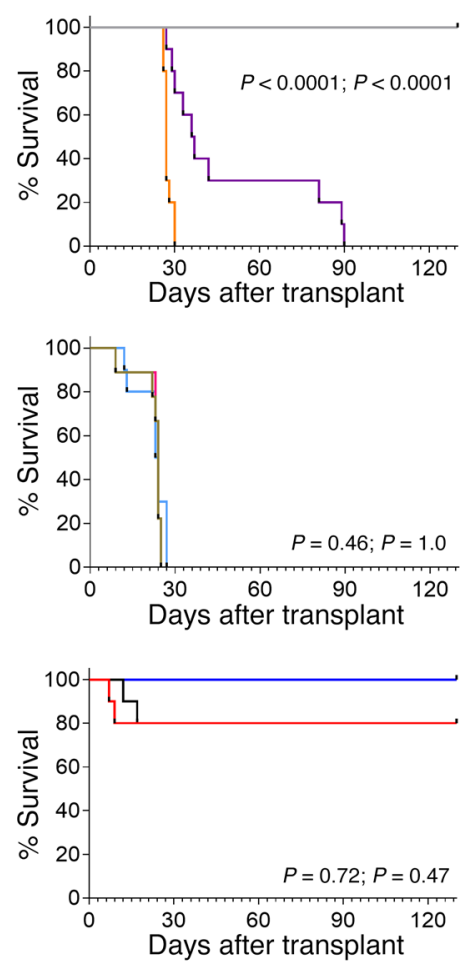

Splenocyte reinfusion day 126
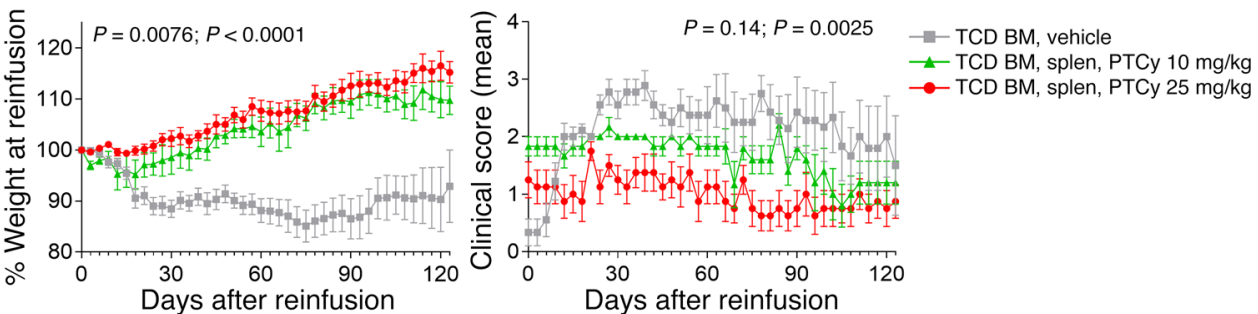

Splenocyte reinfusion day 28
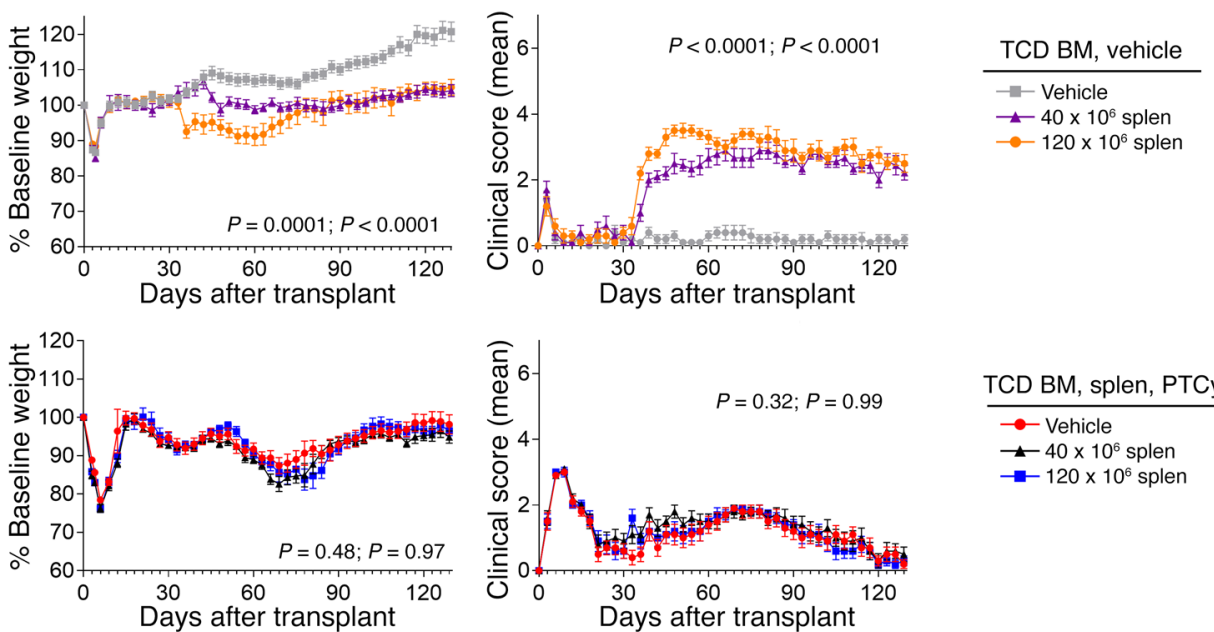

Splenocyte reinfusion day 5
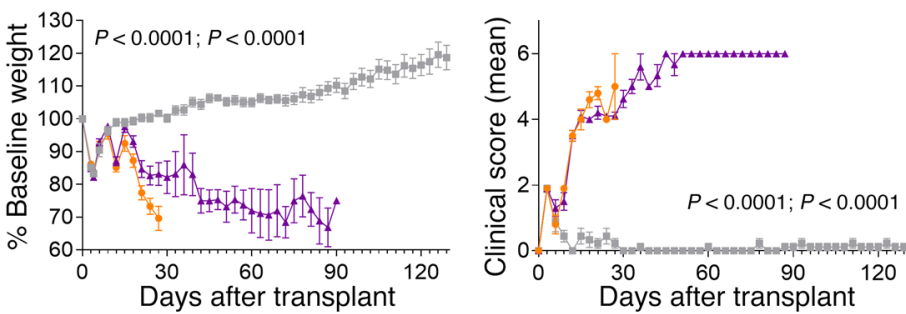

TCD BM, vehicle
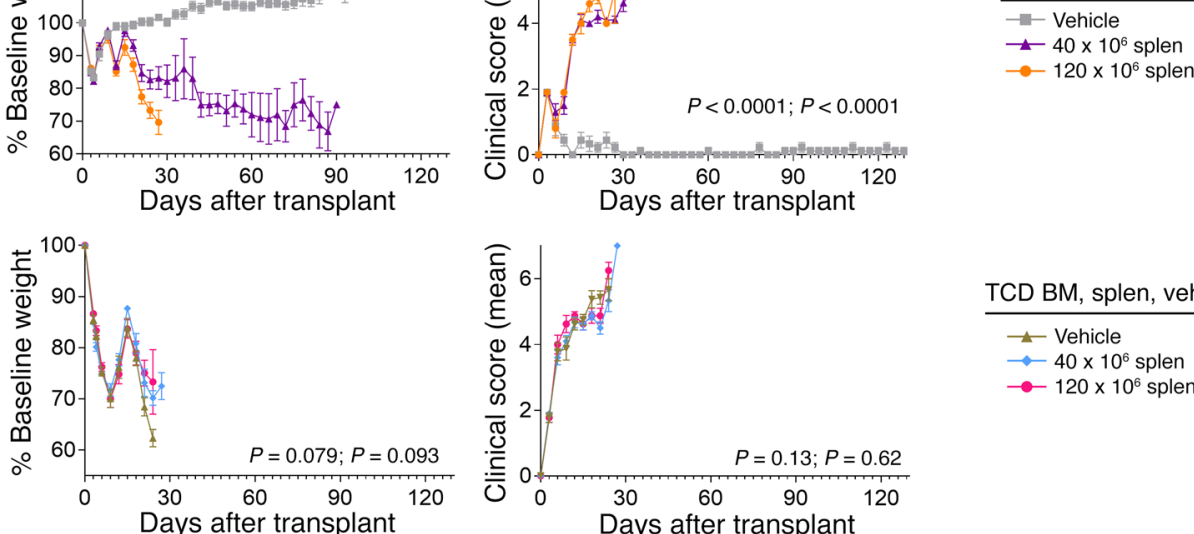

TCD BM, splen, vehicle

$\simeq$ Vehicle

$\rightarrow-40 \times 10^{6}$ splen

$\rightarrow-120 \times 10^{6}$ splen

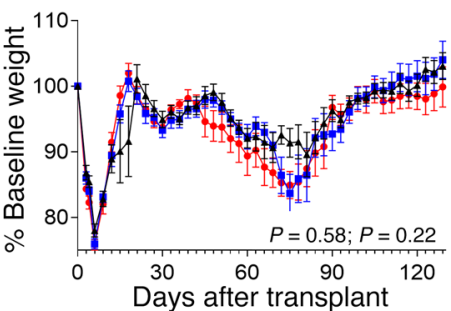

TCD BM, splen, PTCy

$\rightarrow$ Vehicle

$\leftarrow 40 \times 10^{6}$ splen

$\rightarrow-120 \times 10^{6}$ splen

Figure 10. PTCy rapidly induces suppressive mechanisms that prevent new splenocytes not exposed to PTCy from causing GVHD. Recipient B6D2F1 mice were transplanted as in Figure 1 and received vehicle or PTCy on days +3 and +4 . On day $(\mathbf{A})+126,(\mathbf{B})+28$, or $(\mathbf{C})+5$, all groups were reinfused with vehicle or with $40 \times 10^{6}$ or $120 \times 10^{6}$ splenocytes from new 10 - to 12-week-old B6C3F1 donor mice. A shows the original treatments for each group, and all were reinfused with $120 \times 10^{6}$ splenocytes. Survival was compared using the exact log-rank test. Weight and clinical score AUCs were compared using Wilcoxon's rank sum test. AUC comparisons for B are over days +28 to +130 , as the groups were identically treated prior to that time point. All other AUCs are over the entire evaluation period. $P$ values show comparisons between the first and second groups (shown first) and the first and third groups (shown second). 
active $\mathrm{T}$ cells proliferate in response to alloantigen in vivo and in vitro, traffic heavily to GVHD target organs, and do not assume an anergic phenotype, ruling out ignorance and making anergy or the functionally unresponsive form of peripheral tolerance less likely. GVHD prevention by PTCy is not blocked by calcineurin inhibitors (2), also arguing against anergy (56). PTCy's impact is early after transplant, before vehicle-treated mice die of GVHD, making senescence unlikely; senescence also tends to occur after repetitive, rather than excessive and continuous, antigen stimulation (57). Excessive and continuous antigen exposure may lead to T cell exhaustion, which would fit with the functional defects we have observed. Therefore, our current operating hypothesis underlying ongoing work in the laboratory is that PTCy induces alloreactive T cell exhaustion, contributing to GVHD prevention.

Our findings provide fundamental insights that improve our understanding of how PTCy prevents GVHD. These new data should prompt a reevaluation of the currently accepted model and inspire further studies that will result in the development of a comprehensive new model grounded in experimental HCT data and consistent with clinical observations. Ultimately, this work may lay the foundation for the rational development of novel strategies that improve outcomes after PTCy-based HCT and are effective for the induction (or breaking) of tolerance in other clinical contexts.

\section{Methods}

Experimental design. The objective of this controlled laboratory study was to dissect the mechanistic basis for PTCy-mediated GVHD prevention. We specifically tested the hypotheses underlying the existing paradigm: 3 mechanisms are necessary for PTCy's efficacy: (a) selective elimination of alloreactive $\mathrm{T}$ cells, (b) intrathymic clonal deletion, and (c) induction of $\mathrm{CD}^{+} \mathrm{Foxp}^{+}$Tregs. Mice were randomized to each treatment group at the time of irradiation or, for DT depletion at day +150 , at day +150 . Evaluations of clinical scores and weights were performed in a blinded manner by the adjudicator being handed unlabeled cages from another investigator. Coded histopathologic slides were blindly scored by a veterinary pathologist using a standardized scoring rubric (Supplemental Table 1). GVHD experiments were performed with 5 mice/group/experiment and were repeated at least once. Flow cytometric and histopathologic studies within the first posttransplant month were designed using 6 to 8 total mice/group from 2 to 3 experiments. Flow cytometric studies at late posttransplant time points included all survivors of the original GVHD experiments. All data, including outliers, were included with one predetermined exception: flow cytometric cell-subset percentages were considered nonevaluable and excluded if the parent subset contained less than 100 events (i.e., the denominator was $<100$ ).

Mice. B6C3F1/Crl, C57BL/6/NCrl, B6D2F1/Crl, and C3H/ HeNCrl mice were obtained from the Charles River. AKR/J mice were obtained from The Jackson Laboratory. B6.Foxp3-DTR ${ }^{\text {GFP }}$; luc ${ }^{+}$ mice $(34,42)$ were obtained from Leo Luznik (Johns Hopkins University, Baltimore, Maryland, USA) and were bred at the NCI, including the generation of $\mathrm{B} 6 \mathrm{C} 3 \mathrm{~F} 1$ mice using $\mathrm{C} 3 \mathrm{H} / \mathrm{HeNCrl}$ male mice (Charles River) and B6.Foxp3-DTR ${ }^{\text {GFP }}$; luc ${ }^{+}$female mice. B6.Cg-CD8a $<\mathrm{a}>\operatorname{Tg}$ (Tcra2C,Tcrb2C)1Dlo mice (39) were obtained from the RIKEN BioResource Center (developer: Takanori Teshima, Hokkaido University, Sapporo, Hokkaido, Japan) and were bred at the NCI, including the generation of $\mathrm{B} 6 \mathrm{C} 3 \mathrm{~F} 1$ mice using $\mathrm{C} 3 \mathrm{H} / \mathrm{HeNCrl}$ male mice
(Charles River) and B6.Cg-CD8a $<\mathrm{a}>\mathrm{Tg}$ (Tcra2C,Tcrb2C)1Dlo female mice. B6.Cg-Tg(CD2-Tcra,Cd4-Tcrb)4CKang/Mmucd mice (40, 58) were obtained from the Mutant Mouse Resource and Research Center and were bred at the $\mathrm{NCI}$, including the generation of $\mathrm{B} 6 \mathrm{C} 3 \mathrm{~F} 1$ mice using $\mathrm{C} 3 \mathrm{H} / \mathrm{HeNCrl}$ male mice (Charles River Laboratories) and B6.Cg-Tg(CD2-Tcra,Cd4-Tcrb)4CKang/Mmucd female mice. For some experiments, thymectomy was performed by Charles River on B6D2F1 mice at 7 to 8 weeks of age. B6D2F1 mice were nonthymectomized except where specifically noted. All donors and recipients were 10- to 12-week-old female littermate controls except where otherwise specified. All mice were maintained in specific pathogen-free conditions at the NCI, where they were given food and water ad libitum.

HCT. Recipient mice were irradiated to $10.5 \mathrm{~Gy}$ in a single fraction using a Gammacell 40 Cesium-137 irradiator 6 to 8 hours prior to transplantation and were given levofloxacin-treated water (Akorn) from days 0 to +14 . Grafts were resuspended in a total volume of 0.5 $\mathrm{ml}$ RPMI with L-glutamine and administered via tail vein injection. Based on dose titration experiments in the B6C3F1 $\rightarrow$ B6D2F1 model (Supplemental Figure 1) and the desire to keep conditions similar across models, the cell dose for TCD BM was $10 \times 10^{6}$ and for RBC-depleted splenocytes was $40 \times 10^{6}$ cells except where otherwise specified. Mice were followed daily for survival and euthanized if deemed moribund by the veterinary staff. Blinded evaluations of clinical scores and weights were performed every 3 days according to a standardized scoring rubric (Supplemental Figure 23), which was adapted from a previously published rubric (59) to the B6C3F1 $\rightarrow$ B6D2F1 model.

Graft preparation. Following euthanasia with $\mathrm{CO}_{2}$, spleens, tibias, and femurs were aseptically collected from donor mice. Spleens were mechanically disrupted over $70 \mu \mathrm{m}$ nylon cell strainers using culture media (RPMI with L-glutamine, 10\% fetal bovine serum, 1\% sodium pyruvate, $1 \%$ MEM nonessential amino acids, $1 \%$ penicillin/ streptomycin, and $0.1 \%$ mercaptoethanol), RBC lysed twice using ACK Lysis Buffer, and refiltered over $70 \mu \mathrm{m}$ cell strainers. BM was flushed from tibias and femurs using 26-gauge needles over $100 \mu \mathrm{m}$ nylon cell strainers, resuspended at $20 \times 10^{6}$ cells $/ \mathrm{ml}$, and TCD using anti-Thy1.2 antibody (BioXCell) followed by treatment with guinea pig complement (CedarLane).

Graft manipulation. For $2 \mathrm{C} \mathrm{TCR}^{+}$admixed graft preparation, percentages of $\mathrm{T}$ cell subsets in WT or $2 \mathrm{C}$ splenocytes were assessed using flow cytometry and the dose of $2 \mathrm{C} \mathrm{TCR}{ }^{+} \mathrm{T}$ cells was iteratively titered with the goal of $8 \%$ of infused CD $8{ }^{+} \mathrm{T}$ cells being $2 \mathrm{C} \mathrm{TCR}^{+}$(acceptable range $7.2 \%-8.8 \%$ ). $4 \mathrm{C} \mathrm{TCR}^{+}$admixed grafts were prepared similarly by combining and titering WT and $4 \mathrm{C} \mathrm{TCR}^{+}$splenocytes with the goal of $8 \%$ of infused $\mathrm{CD}^{+} \mathrm{T}$ cells being $4 \mathrm{C} \mathrm{TCR}^{+}$(acceptable range 7.2\%-8.8\%). To prepare Treg-depleted or Treg-selected grafts, the $\mathrm{CD} 4{ }^{+} \mathrm{CD} 25^{+}$Regulatory $\mathrm{T}$ cell Isolation Kit (Miltenyi Biotec) and an autoMACS Pro Separator (Miltenyi Biotec) were used as per the manufacturer's protocol with a single modification in that the $\mathrm{CD} 4^{+} \mathrm{CD} 25^{-}$ fraction underwent a second depletion using the DEPL025 program to further reduce contaminating $\mathrm{CD} 4{ }^{+} \mathrm{CD} 25^{+}$cells.

Drug preparation and administration. Cyclophosphamide (Baxter Oncology) was reconstituted in sterile PBS at 5 or $10 \mathrm{mg} / \mathrm{ml}$, aliquoted, and cryopreserved at $-80^{\circ} \mathrm{C}$ until the day of administration. At that time, an aliquot was thawed and diluted with sterile PBS to a concentration (depending on dose) that allowed for the administration of approximately 400-500 $\mu$ l per mouse. DT (MilliporeSigma) was reconstituted at $2 \mathrm{mg} / \mathrm{ml}$ in sterile PBS, aliquoted, and cryopreserved 
at $-20^{\circ} \mathrm{C}$ until the day of administration. At that time, an aliquot was thawed and diluted with sterile PBS to a concentration of $1 \mu \mathrm{g} / \mathrm{ml}$ for injection. The same thawed vial was refrozen at $-20^{\circ} \mathrm{C}$ for use for the next day's dosing. DT aliquots were never freeze-thawed more than 1 time. Cyclophosphamide or DT were administered intraperitoneally at approximately 24-hour intervals (e.g., day +3 means $~ 72$ hours after transplant). Doses were based on the weight on the day of injection. Mice not receiving the drug were always given similar volumes of PBS vehicle intraperitoneally.

Histopathologic specimen preparation. Following $\mathrm{CO}_{2}$ euthanasia, a section of left flank skin, 2 sections of liver, and 2 halves of the stomach were collected and placed in a $10 \%$ formalin solution (MilliporeSigma). The entirety of the intestines was intraluminally instilled with formalin and then placed in formalin in cassettes. For certain experiments, eyes, eyelids including conjunctiva, Harderian glands, and exorbital lacrimal glands were obtained, placed in cassettes, and fixed in formalin. For some experiments, lungs, heart, and kidneys also were collected. Lungs were intraluminally instilled with 2 to $3 \mathrm{ml}$ of formalin via tracheal injection, placed whole along with the heart into a cassette, and placed in formalin. Kidneys were bisected in the coronal section and placed in cassettes in formalin. Complete autopsies were performed by veterinary pathologists and examined the skin, liver, stomach, small intestine, cecum, colon, lungs, heart, and kidneys as above, but also included the ovaries, uterus, brain, adrenal glands, spleen, thymus, and BM. All formalin-fixed tissue specimens were sent to Histoserv Inc. for paraffin embedding, slide preparation, and H\&E staining.

Tissue processing for flow cytometric analysis. Mice were anesthetized using isoflurane and then terminally bled retroorbitally. Blood was collected via heparinized tubes into Eppendorf tubes containing $10 \mu \mathrm{l}$ heparin (10,000 USP units per ml) and mixed immediately. Following blood collection, euthanasia of each animal was ensured using $\mathrm{CO}_{2}$. Spleens and peripheral (cervical, axillary, brachial, and inguinal) lymph nodes were collected. Livers were flushed of peripheral blood by cutting the portal vein and forcefully injecting $10 \mathrm{ml}$ of sterile PBS into the heart, causing it to exsanguinate the liver. Spleens and lymph nodes were disrupted over $70 \mu \mathrm{m}$ nylon cell strainers. Blood was RBC lysed twice, and spleens were RBC-lysed once using ACK lysis buffer. Livers were mechanically disrupted over $100 \mu \mathrm{m}$ nylon cell strainers, RBC lysed, and subjected to density gradient centrifugation with $36 \%$ Percoll (GE Healthcare).

Flow cytometry. Up to $3 \times 10^{6}$ viable cells/sample were stained sequentially with the LIVE/DEAD Fixable Aqua Dead Cell Stain Kit (Thermo Fisher), extracellular antibodies, fixation/permeabilization (eBioscience Foxp3 Staining Kit), and intracellular antibodies. Single stains were prepared to generate compensations, and fluorescence-minus-one controls were prepared for specific markers (e.g., CD25 and Ki-67). Flow cytometric analysis examining leukocytes other than T cells also were treated with Mouse FC Block (BD Biosciences, clone 2.4G2) prior to extracellular antibody staining. Data were acquired on BD Fortessa or BD LSR II flow cytometers and analyzed using FACSDiva 8.0.1. Flow cytometric cell sorting was performed on a BD Influx.

Fluorochrome-conjugated monoclonal antibodies used for flow cytometry included PerCP-Cy5.5 anti-B220 (clone RA3-6B2), APC-efluor780 anti-CD4 (clone GK1.5), efluor450 and APC antiFoxp3 (clone FJK-16S), PE-Cy7 anti-H2k ${ }^{\mathrm{b}}$ (clone AF6-88.5.5.3), and
PerCP-efluor710 anti-VB6 (clone RR4-7) from eBioscience; BUV395 anti-CD3 (clone 145-2611), BUV661 anti-CD11b, FITC anti-CD19 (clone 1D3), PE-CF594 anti-CD25 (clone PC61), AF700 anti-CD44 (clone 1M7), PE anti-CD45.1 (clone A20), BUV737 anti-CD62L (clone MEL-14), BV786 anti-folate receptor 4 (FR4; clone 12A5), PE H2k ${ }^{\mathrm{k}}$

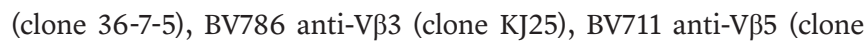
MR9-4), and FITC V $\beta 13$ (clone MR12-3) from BD Biosciences; and PE-Cy5 anti-CD8 (clone 53-6.7), APC anti-CD73 (clone TY/11.8), PE-Cy7 anti-H2k ${ }^{\mathrm{d}}$ (clone SF1-1.1), BV605 anti-Ki-67 (clone 1GA8), BV421 anti-NK1.1 (clone PK136), AF647 anti-Thy1.2 (clone 30-H12), PE-Cy5 anti-Thy1.2 (clone 53-2.1), and AF647 anti-Vß8.1/8.2 from BioLegend. An FITC-conjugated 1B2 antibody (39), specific for the 2C TCR, was obtained in house.

Mixed lymphocyte cultures. Liver-infiltrating mononuclear cells were aseptically isolated from PBS-flushed livers as above. Unfractionated mononuclear cells or flow cytometrically sorted $\mathrm{T}$ cell fractions were stained with $2.5 \mu \mathrm{M}$ CellTrace Violet (Thermo Fisher) per the manufacturer's instructions. Stimulator cells were obtained by spleen disruption and $\mathrm{RBC}$ lysis as above prior to irradiation to 30 Gy in a single faction using a Gammacell 1000 irradiator. Cells were plated at a 1:1 ratio of $2 \times 10^{5}$ live responders to $2 \times 10^{5}$ irradiated splenocyte stimulators in a total volume of $200 \mu \mathrm{l}$ of cell culture media in round-bottom 96 -well plates and incubated at $37^{\circ} \mathrm{C}$ with $5 \% \mathrm{CO}_{2}$. At 24 hours after placing into culture, supernatant was isolated from some wells and cryopreserved at $-20^{\circ} \mathrm{C}$ for cytokine analysis and the cells discarded. At 5 days of culture, the remaining cultured cells were processed for flow cytometric analysis.

Cytokine analysis. Cryopreserved cell culture supernatants were thawed and analyzed using ProcartaPlex Custom 9-Plex Assays (Thermo Fisher) according to the manufacturer's instructions, with analysis by a Luminex 200 .

DNA methylation analysis. Dry pellets of flow cytometrically sorted $\mathrm{CD}^{+}{ }^{+} \mathrm{T}$ cell subsets were snap-frozen, stored at $-80^{\circ} \mathrm{C}$, and then shipped on dry ice to EpigenDx for DNA extraction, bisulfite modification, and pyrosequencing in triplicate of $4 \mathrm{CpG}$ sites within intron 1 of the mouse Foxp3 TSDR (assay ID ADS568-FS2).

Time points. For flow cytometric and histopathologic data, days +6 and +7 refer to the sixth and seventh days after transplant, respectively. Day +21 refers to days $+20-22$. Day +50 refers to days $+49-50$. Day +150 refers to days $+145-158$. Day +200 refers to days $+200-210$.

Statistics. Survival distributions were compared using the exact log-rank test. Point-wise weight comparisons and weight and clinical score AUC comparisons were performed using Wilcoxon's rank sum test. Point-wise clinical score comparisons were performed using the Cochrane-Armitage test for trend. Weight and clinical score data are shown as the mean \pm SEM. Cell subset percentages were transformed using an Arcsin transformation prior to 1-way ANOVA or $t$ test. Cell counts and cytokine values were natural logarithmically transformed prior to 1-way ANOVA or $t$ test. Undetectable cytokine levels were assigned a value of 0.01 prior to transformation. Comparisons of cytokine levels in supernatant underwent the Holm-Šidák correction to account for multiple testing. ANOVAs, when significant, were followed with the Holm-Šidák post hoc test. The transformed data were used for statistical testing, but the nontransformed data are displayed for clarity of understanding and are shown as box-and-whisker plots. SAS/STAT (SAS), version 12, was used for analyses of survival, weight, and clinical score data. GraphPad Prism (GraphPad Software), version 
7.01, was used for all other statistical analyses and for data presentation. All analyses were 2 tailed. $P$ values of less than 0.05 were considered statistically significant.

Study approval. Mice were treated under a protocol approved by the NCI Animal Care and Use Committee in accordance with the NIH Guide for the Care and Use of Laboratory Animals (National Academies Press, 2011).

\section{Author contributions}

CGK designed the study. LPW, MTP, and REG contributed to the study design. LPW, MTP, and CGK performed experiments and analyzed data. MAE performed blinded assessments of histopathology. DJV designed and performed the statistical analyses. All authors interpreted data. LPW and CGK designed and created the tables and figures. CGK wrote the manuscript, and all authors edited the manuscript.

\section{Acknowledgments}

This work was supported by the Intramural Research Program of the NCI, NIH. We would like to thank Devorah Gallardo, Ehydel Castro, Veena Kapoor, and William Telford for technical assistance.

Address correspondence to: Christopher G. Kanakry, Building 10-CRC, Room 4-3142, 10 Center Drive, Bethesda, Maryland 20892, USA. Phone: 240.760.6171; Email: christopher.kanakry@ nih.gov.
1. Gragert L, et al. HLA match likelihoods for hematopoietic stem-cell grafts in the U.S. registry. N Engl J Med. 2014;371(4):339-348.

2. Kanakry CG, Fuchs EJ, Luznik L. Modern approaches to HLA-haploidentical blood or marrow transplantation. Nat Rev Clin Oncol. 2016;13(1):10-24.

3. Szydlo R, et al. Results of allogeneic bone marrow transplants for leukemia using donors other than HLA-identical siblings. J Clin Oncol. 1997;15(5):1767-1777.

4. Kanakry CG, et al. Low immunosuppressive burden after HLA-matched related or unrelated BMT using posttransplantation cyclophosphamide. Blood. 2017;129(10):1389-1393.

5. McCurdy SR, et al. Grade II acute graft-versushost disease and higher nucleated cell graft dose improve progression-free survival after HLA-haploidentical transplant with post-transplant cyclophosphamide. Biol Blood Marrow Transplant. 2018;24(2):343-352.

6. Kanakry JA, et al. Absence of post-transplantation lymphoproliferative disorder after allogeneic blood or marrow transplantation using post-transplantation cyclophosphamide as graft-versus-host disease prophylaxis. Biol Blood Marrow Transplant. 2013;19(10):1514-1517.

7. Crocchiolo R, et al. Infections after T-replete haploidentical transplantation and high-dose cyclophosphamide as graft-versus-host disease prophylaxis. Transpl Infect Dis. 2015;17(2):242-249.

8. Tischer J, et al. Virus infection in HLA-haploidentical hematopoietic stem cell transplantation: incidence in the context of immune recovery in two different transplantation settings. Ann Hematol. 2015;94(10):1677-1688.

9. Kanakry CG, et al. Origin and evolution of the T cell repertoire after posttransplantation cyclophosphamide. JCI Insight. 2016;1(5):e86252.

10. McCurdy SR, et al. Risk-stratified outcomes of nonmyeloablative HLA-haploidentical BMT with high-dose posttransplantation cyclophosphamide. Blood. 2015;125(19):3024-3031.

11. Ciurea SO, et al. Haploidentical transplant with posttransplant cyclophosphamide vs matched unrelated donor transplant for acute myeloid leukemia. Blood. 2015;126(8):1033-1040.

12. Kanate AS, et al. Reduced-intensity transplantation for lymphomas using haploidentical related donors vs HLA-matched unrelated donors. Blood.
2016;127(7):938-947.

13. Ghosh N, et al. Reduced-intensity transplantation for lymphomas using haploidentical related donors versus HLA-matched sibling donors: a center for international blood and marrow transplant research analysis. J Clin Oncol. 2016;34(26):3141-3149.

14. Majzner RG, et al. Post-transplantation cyclophosphamide after bone marrow transplantation is not associated with an increased risk of donor-derived malignancy. Biol Blood Marrow Transplant. 2017;23(4):612-617.

15. Luznik L, Jalla S, Engstrom LW, Iannone R, Fuchs EJ. Durable engraftment of major histocompatibility complex-incompatible cells after nonmyeloablative conditioning with fludarabine, low-dose total body irradiation, and posttransplantation cyclophosphamide. Blood. 2001;98(12):3456-3464.

16. Mayumi H, Good RA. Long-lasting skin allograft tolerance in adult mice induced across fully allogeneic (multimajor $\mathrm{H}-2$ plus multiminor histocompatibility) antigen barriers by a tolerance-inducing method using cyclophosphamide. J Exp Med.1989;169(1):213-238.

17. Mayumi H, Umesue M, Nomoto K. Cyclophosphamide-induced immunological tolerance: an overview. Immunobiology. 1996;195(2):129-139.

18. Hodes RJ, Abe R. Mouse endogenous superantigens: Ms and Mls-like determinants encoded by mouse retroviruses. Curr Protoc Immunol. 2001;Appendix 1:Appendix 1F.

19. Eto M, et al. Specific destruction of host-reactive mature $\mathrm{T}$ cells of donor origin prevents graftversus-host disease in cyclophosphamideinduced tolerant mice. J Immunol. 1991;146(5):1402-1409.

20. Eto M, Mayumi H, Tomita Y, Yoshikai Y, Nishimura Y, Nomoto K. Sequential mechanisms of cyclophosphamide-induced skin allograft tolerance including the intrathymic clonal deletion followed by late breakdown of the clonal deletion. J Immunol. 1990;145(5):1303-1310.

21. Eto M, Mayumi H, Tomita Y, Yoshikai Y, Nishimura Y, Nomoto K. The requirement of intrathymic mixed chimerism and clonal deletion for a long-lasting skin allograft tolerance in cyclophosphamide-induced tolerance. Eur JImmunol. 1990;20(9):2005-2013.

22. Eto M, Mayumi H, Tomita Y, Yoshikai Y, Nomoto
K. Intrathymic clonal deletion of $\mathrm{V}$ beta $6+\mathrm{T}$ cells in cyclophosphamide-induced tolerance to $\mathrm{H}$-2-compatible, Mls-disparate antigens. J Exp Med.1990;171(1):97-113.

23. Kong YY, Eto M, Omoto K, Umesue M, Hashimoto A, Nomoto K. Regulatory T cells in maintenance and reversal of peripheral tolerance in vivo. J Immunol. 1996;157(12):5284-5289.

24. Tomita Y, Mayumi H, Eto M, Nomoto K. Importance of suppressor T cells in cyclophosphamide-induced tolerance to the non-H-2-encoded alloantigens. Is mixed chimerism really required in maintaining a skin allograft tolerance? J Immunol.1990;144(2):463-473.

25. Mayumi H, Himeno K, Tokuda N, Nomoto K. Drug-induced tolerance to allografts in mice. VII. Optimal protocol and mechanism of cyclophosphamide-induced tolerance in an $\mathrm{H}-2$ haplotype-identical strain combination. Transplant Proc. 1986;18(2):363-369.

26. Mayumi H, Good RA. The necessity of both allogeneic antigens and stem cells for cyclophosphamide-induced skin allograft tolerance in mice. Immunobiology. 1989;178(4-5):287-304.

27. Mayumi H, Good RA. Dependency of cyclophosphamide-induced skin allograft tolerance on age of adult recipient mice. Transplantation. 1988;46(3):451-453.

28. Mayumi H, Good RA. Induction of tolerance across major barriers using a two-step method with genetic analysis of tolerance induction. Immunobiology. 1989;179(1):86-108.

29. Kasamon YL, et al. Outcomes of nonmyeloablative HLA-haploidentical blood or marrow transplantation with high-dose post-transplantation cyclophosphamide in older adults. JClin Oncol. 2015;33(28):3152-3161.

30. Kanakry CG, et al. Multi-institutional study of post-transplantation cyclophosphamide as singleagent graft-versus-host disease prophylaxis after allogeneic bone marrow transplantation using myeloablative busulfan and fludarabine conditioning. JClin Oncol. 2014;32(31):3497-3505.

31. Kanakry CG, et al. Single-agent GVHD prophylaxis with posttransplantation cyclophosphamide after myeloablative, HLA-matched BMT for AML, ALL, and MDS. Blood. 2014;124(25):3817-3827.

32. Mielcarek M, et al. Posttransplantation cyclophosphamide for prevention of graft-versus-host disease after HLA-matched mobilized blood cell 
transplantation. Blood. 2016;127(11):1502-1508.

33. Kanakry CG, et al. Aldehyde dehydrogenase expression drives human regulatory $\mathrm{T}$ cell resistance to posttransplantation cyclophosphamide. Sci Transl Med. 2013;5(211):211ra157.

34. Ganguly S, et al. Donor CD4+ Foxp3+ regulatory $\mathrm{T}$ cells are necessary for posttransplantation cyclophosphamide-mediated protection against GVHD in mice. Blood. 2014;124(13):2131-2141.

35. Ross D, Jones M, Komanduri K, Levy RB. Antigen and lymphopenia-driven donor $\mathrm{T}$ cells are differentially diminished by post-transplantation administration of cyclophosphamide after hematopoietic cell transplantation. Biol Blood Marrow Transplant. 2013;19(10):1430-1438.

36. Cieri N, et al. Generation of human memory stem $\mathrm{T}$ cells after haploidentical T-replete hematopoietic stem cell transplantation. Blood. 2015;125(18):2865-2874.

37. Roberto $\mathrm{A}$, et al. Role of naive-derived $\mathrm{T}$ memory stem cells in T-cell reconstitution following allogeneic transplantation. Blood. 2015;125(18):2855-2864.

38. Luznik L, O’Donnell PV, Fuchs EJ. Post-transplantation cyclophosphamide for tolerance induction in HLA-haploidentical bone marrow transplantation. Semin Oncol. 2012;39(6):683-693.

39. Sha WC, Nelson CA, Newberry RD, Kranz DM, Russell JH, Loh DY. Selective expression of an antigen receptor on CD8-bearing T lymphocytes in transgenic mice. Nature. 1988;335(6187):271-274.

40. Brennan TV, et al. A new T-cell receptor transgenic model of the $\mathrm{CD} 4+$ direct pathway: level of priming determines acute versus chronic rejection. Transplantation. 2008;85(2):247-255.

41. Kalekar LA, et al. CD4(+) T cell anergy prevents autoimmunity and generates regulatory $\mathrm{T}$ cell precursors. Nat Immunol. 2016;17(3):304-314.
42. Kim JM, Rasmussen JP, Rudensky AY. Regulatory $\mathrm{T}$ cells prevent catastrophic autoimmunity throughout the lifespan of mice. Nat Immunol. 2007;8(2):191-197.

43. Nguyen $\mathrm{VH}$, et al. In vivo dynamics of regulatory T-cell trafficking and survival predict effective strategies to control graft-versus-host disease following allogeneic transplantation. Blood. 2007;109(6):2649-2656.

44. Di Ianni M, et al. Tregs prevent GVHD and promote immune reconstitution in HLA-haploidentical transplantation. Blood. 2011;117(14):3921-3928.

45. Said R, Abdel-Rehim M, Sadeghia B, Al-Hashemi S, Hassan M. Cyclophosphamide pharmacokinetics in mice: a comparison between retro orbital sampling versus serial tail vein bleeding. The Open Pharmacology Journal. 2007;1:30-35.

46. Kanakry CG, Luznik L. Teaching a young dog new tricks: modifications to the post-transplantation cyclophosphamide haploidentical transplantation platform. Biol Blood Marrow Transplant. 2018;24(6):1108-1110.

47. McCurdy SR, et al. Development of grade II acute graft-versus-host disease is associated with improved survival after myeloablative HLAmatched bone marrow transplantation using single-agent post-transplant cyclophosphamide [published online ahead of print December 16, 2018]. Biol Blood Marrow Transplant. https://doi. org/10.1016/j.bbmt.2018.12.767.

48. Bradstock KF, et al. Single-agent high-dose cyclophosphamide for graft-versus-host disease prophylaxis in human leukocyte antigen-matched reduced-intensity peripheral blood stem cell transplantation results in an unacceptably high rate of severe acute graft-versus-host disease. Biol Blood Marrow Transplant. 2015;21(5):941-944.

49. Holtick U, et al. OCTET-CY: a phase II study to investigate the efficacy of post-transplant cyclophosphamide as sole graft-versus-host prophylaxis after allogeneic peripheral blood stem cell transplantation. Eur J Haematol. 2016;96(1):27-35.

50. Legoux FP, et al. CD4+ T cell tolerance to tissue-restricted self antigens is mediated by antigen-specific regulatory $\mathrm{T}$ cells rather than deletion. Immunity. 2015;43(5):896-908.

51. Yu W, et al. Clonal deletion prunes but does not eliminate self-specific $\alpha \beta C D 8(+)$ T lymphocytes. Immunity. 2015;42(5):929-941.

52. Koreth J, et al. Interleukin-2 and regulatory $\mathrm{T}$ cells in graft-versus-host disease. $N$ Engl J Med 2011;365(22):2055-2066.

53. Zheng J, et al. Human CD8+ regulatory T cells inhibit GVHD and preserve general immunity in humanized mice. Sci Transl Med. 2013;5(168):168ra9.

54. Tsai S, Clemente-Casares X, Santamaria P. CD8(+) Tregs in autoimmunity: learning "self"-control from experience. Cell Mol Life Sci. 2011;68(23):3781-3795.

55. Schietinger A, Greenberg PD. Tolerance and exhaustion: defining mechanisms of $\mathrm{T}$ cell dysfunction. Trends Immunol. 2014;35(2):51-60.

56. Fathman CG, Lineberry NB. Molecular mechanisms of CD4+ T-cell anergy. Nat Rev Immunol. 2007;7(8):599-609.

57. Wherry EJ, Kurachi M. Molecular and cellular insights into T cell exhaustion. Nat Rev Immunol. 2015;15(8):486-499.

58. Brennan TV, et al. Preferential priming of alloreactive $\mathrm{T}$ cells with indirect reactivity. Am J Transplant. 2009;9(4):709-718.

59. Cooke KR, et al. An experimental model of idiopathic pneumonia syndrome after bone marrow transplantation: I. The roles of minor $\mathrm{H}$ antigens and endotoxin. Blood.1996;88(8):3230-3239. 